110 Nordic Council of Ministers

\title{
KNOWLEDGE THAT WORKS IN PRACTICE
}

Strengthening Nordic co-operation in the social field

BY ÁRNI PÁLL ÁRNASON 
KNOWLEDGE THAT WORKS IN PRACTICE

Strengthening Nordic co-operation in the social field

Árni Páll Árnason

ANP 2018:822

ISBN 978-92-893-5838-5 (PRINT)

ISBN 978-92-893-5839-2 (PDF)

ISBN 978-92-893-5840-8 (EPUB)

http://dx.doi.org/10.6027/ANP2018-822

(c) Nordic Council of Ministers 2018

Layout: Louise Jeppesen

Cover Photo: Johnér

Print: Rosendahls

Printed in Denmark

\section{Nordic co-operation}

Nordic co-operation is one of the world's most extensive forms of regional collaboration, involving Denmark, Finland, Iceland, Norway, Sweden, the Faroe Islands, Greenland, and Åland.

Nordic co-operation has firm traditions in politics, the economy, and culture. It plays an important role in European and international collaboration, and aims at creating a strong Nordic community in a strong Europe.

Nordic co-operation seeks to safeguard Nordic and regional interests and principles in the global community. Shared Nordic values help the region solidify its position as one of the world's most innovative and competitive.

Nordic Council of Ministers

Nordens Hus

Ved Stranden 18

DK-1061 Copenhagen K

www.norden.org

Download and order Nordic publications from www.norden.org/nordpub 


\section{KNOWLEDGE THAT \\ WORKS IN PRACTICE}

Strengthening Nordic co-operation in the social field 



\section{Content}

Foreword

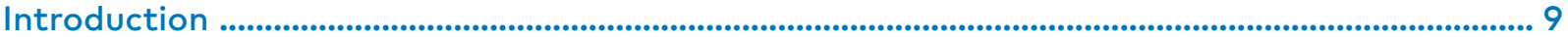

Towards a more knowledge-based and demand-oriented Nordic co-operation in the social field

1. Systematic co-operation on knowledge and initiatives that work in the social field .......................... 13

2. A more knowledge-based and demand-oriented co-operation ................................................................. 14

3. Development of organisational structures ………................................................................................... 16

Key themes for Nordic co-operation in the social field ........................................................................... 19

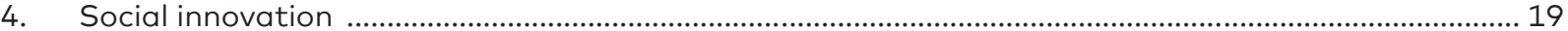

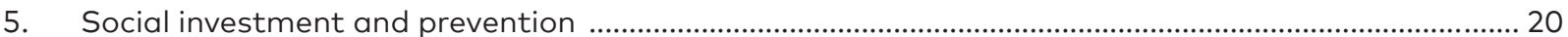

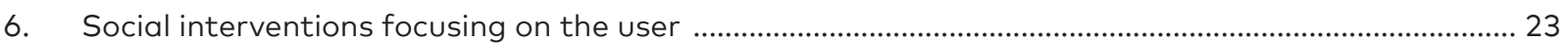

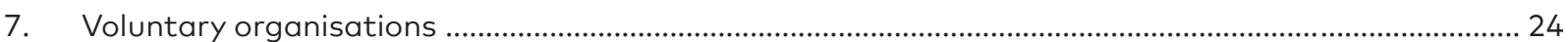

Strengthened Nordic co-operation on children and young people, vulnerable adults, the elderly

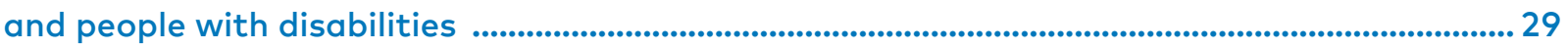

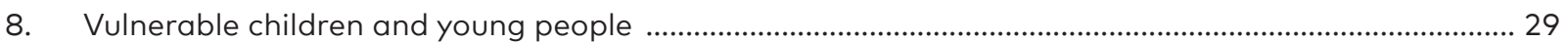

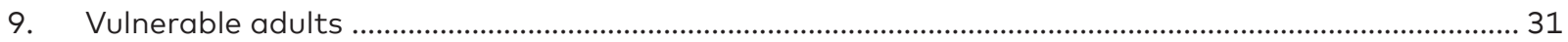

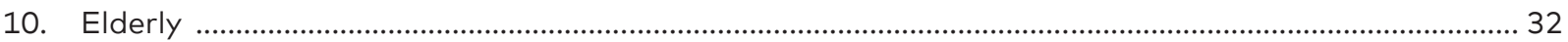

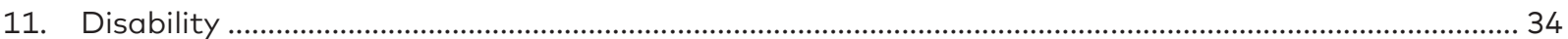

Social initiatives in a broader perspective ............................................................................................ 37

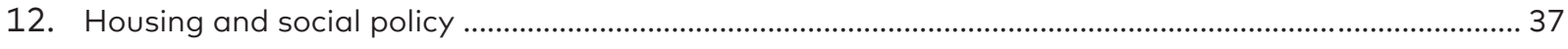

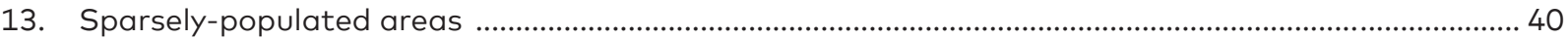

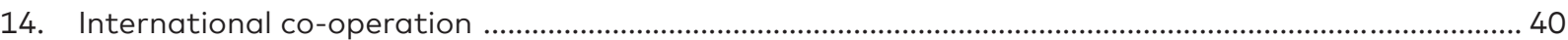




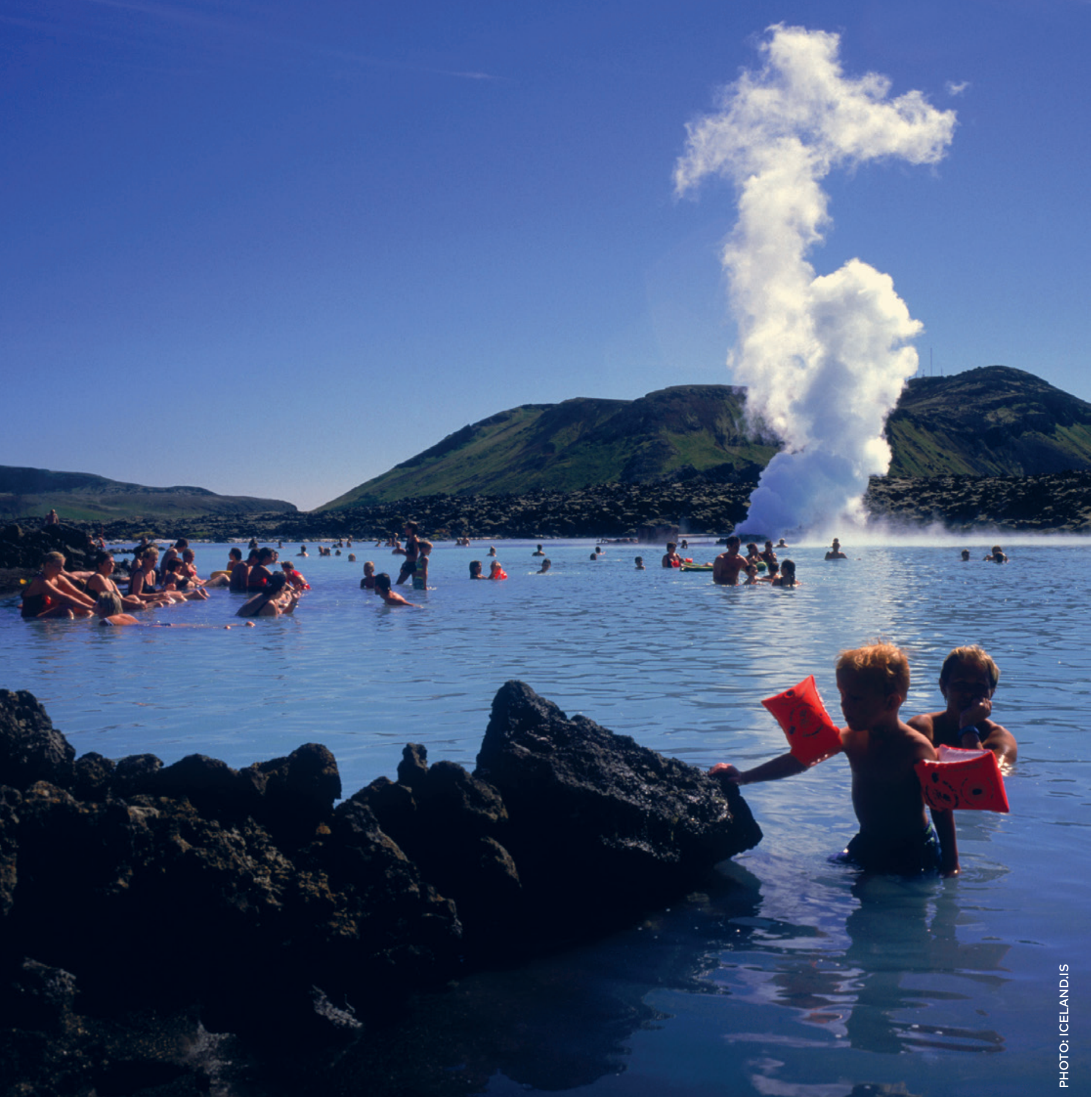




\section{Foreword}

I was very honoured when I was asked by Dagfinn Høybråten, Secretary General of the Nordic Council of Ministers, to lead the strategic review of the Nordic co-operation in the social sector that the Nordic Council of Ministers for Health and Social Affairs had decided to carry out.

The social field is a fundamental building block in the Nordic welfare model, and, as a former Minister of Social Affairs and Social Security and Minister of Economic Affairs in Iceland in the wake of the financial crisis, I know from experience just how important the Nordic welfare model is, and that we should never take it for granted.

With the challenges facing the Nordic welfare model, including with regard to the demographic trends, innovation opportunities and world economic conditions, it is essential to examine how the Nordic co-operation in the social field can be strengthened - both in order to safeguard the Nordic welfare model and to renew it, thereby helping to ensure social security for the citizens of the Nordic region and cement the vanguard position of the Nordic nations in this area.

The aim of this review of the Nordic co-operation in the social sector is to develop and strengthen the co-operation in the social field, as well as to ensure that it is adapted to the needs of the Nordic countries and the relevant issues, and that it produces concrete results. It has been important to me to ensure that the review should not be an academic analysis of the possibilities and challenges for the Nordic welfare model or the social sector in the Nordic countries. My aim has rather been to draw up an action-oriented report, based on a thorough understanding of the current challenges that we face, and to come up with proposals that could contribute to stronger cooperation in the Nordic region in the field of social affairs.
In connection with my work on this review, I have visited all of the Nordic countries: Denmark, Finland, Iceland, Norway and Sweden, as well as the Faroe Islands, Greenland and Åland. I have also held meetings with the European Commission and the European Parliament in Brussels, and with the OECD in Paris. I have calculated that I have visited more than 200 actors in the social field in the various countries, including ministers, public authorities, researchers, interest organisations and voluntary social organisations. These were very good meetings with interesting discussions, and I gained a lot of knowledge, ideas and inspiration from them. My sincere thanks to all those who took part.

It is on the basis of these visits that I am presenting my 14 proposals in this report for strengthening the Nordic co-operation in the social field. This extensive scope does however mean that the report endeavours to paint a picture in broad strokes, and does not therefore take into account everything that I have heard, seen and discussed. The selection of these proposals, and the formulations in the report, are solely my responsibility.

I would like to extend my warmest thanks to senior advisor Søren Stokholm Thomsen, senior advisor Kåre Geil and junior officer Johanna Larby of the Secretariat to the Nordic Council of Ministers, who have been involved all the way through, and who have helped me to develop and formulate ideas and provided me with a great deal of help in the preparation of this report.

\section{I hope you enjoy reading it.}

\section{Árni Páll Árnason Stockholm, 16 October 2018}




\section{Introduction}

I am sometimes asked if there really is such a thing as the Nordic welfare model. It is a good question. The Nordic region consists of a number of different countries with different historical developments that have led to their current status as welfare societies. At one of the many meetings I have had in connection with this project, I was told that a well-known Nordic politician once answered 'yes' to this question, and then added that you could compare the five Nordic countries to five sisters who each married men of different nationalities. Their households were naturally different, but there were also very strong common features. The anecdote may not be true, but in my view it reflects an important insight. We each do things in our own way, but we have a clear common foundation: a solid range of welfare services, the universal right to tax-funded welfare, a strong tripartite co-operation, a key role for municipalities in service provision, and an active civil society.

The Nordic welfare model has proven its relevance and durability. It has managed to eradicate hunger, poverty and disease, and create societies that are more equal than most other countries, and which allow for greater social mobility. The social results in the Nordic countries score consistently highest in international comparisons. But today, we are also facing new and different challenges.

The classic welfare state has often been perceived primarily in terms of the distribution of benefits and the provision of services by paid professionals. This is to some extent correct, but the welfare state is also the manifestation of a partnership with voluntary groups and the labour market partners. In recent decades, the content and delivery of welfare services has been increasingly determined and organised by the public authorities. This has brought about many benefits, but it has also made our systems more rigid and bureaucratic, and less flexible than we would like them to be. Moreover, our systems are often oriented more towards the producer than the user, which can weaken our ability to respond rapidly to new challenges and find new solutions.

We can also observe that there is no one single cause of many of the most difficult social challenges that we face. We can see that social isolation and loneliness is a growing phenomenon throughout our society - from childhood to old age. We see examples of social inequality and social exclusion being inherited between generations. All of the Nordic countries have structural weaknesses when it comes to dealing with complex societal challenges that require co-ordinated action across sectors, regardless of whether these concern health, the labour market, education or housing. There are far too many examples of a failure to address these challenges, and of attempts to find solutions that come to nothing because our systems are structured in 'silos', in which no-one is responsible for finding a comprehensive solution for the individual. And while nobody can seriously doubt the ability of the public sector to handle many social challenges, the public bodies lack the prerequisites to solve problems like social isolation and loneliness. Here we need to develop and strengthen our various social networks: family, friendship, peer support, the efforts of voluntary organisations and local communities. 
One of the most remarkable things I have encountered in my work with this study has been the overall viewpoint of everyone involved - from ministers to government officials, volunteer organisations and users - that we have a far too weak knowledge base for our social initiatives. We lack knowledge of what works, we lack strategies for how we can systematically integrate new and better methods into our social services, and we lack procedures to stop using methods that do not work. We need to recognise - especially when we view the social sector in relation to other sectors the importance of investing in social initiatives and thereby also investing in building up and applying knowledge of what works.

This lack of a strong knowledge-based starting-point for our social welfare solutions is a well-known phenomenon throughout the Western world. Historically, this has been attributed to the need to intervene quickly, which meant there was no time to try out different solutions - together with the politicians' fear of appearing paralysed while different solutions were being tried out. Recently, however, the building of competence in evaluation and impact assessment in the social sphere, together with the technological advances, has made it much easier for us to try out different solutions, while the platform economy provides inspiration and opportunities to further develop citizens' initiatives and solutions worked out by civil society. The biggest challenges we face today are moreover so complex that potential solutions can prove too expensive and too ineffective if we fail to test them and develop them gradually over a period of time. The Nordic countries have many similarities and shared values in social policy, and we therefore have ample opportunity to jointly test different solutions and help to propagate those that work, and remove those that do not. Moreover, in our day, voters do not have much time for politicians who think they have the answer to everything, but who in reality do not have the answer to anything. We have a lot to gain by anchoring politics and political solutions in evidence and facts - especially if the alternative is to make decisions on the basis of preconceived opinions.

In order to do this efficiently, we need to be more open towards social innovation in our systems, strive to work together to build a strong conceptual framework for innovative thinking, and exchange knowledge and experience internally in the Nordic region. We must continue the work of developing and testing interventions and giving new, effective solutions a better chance of finding their way into our systems and becoming established. If we fail to do this, we risk being overtaken by others; all around the world, there are countries that are growing economically stronger and experiencing greater and greater welfare needs, but which are not blessed - or burdened - with structures that have existed for many decades. These countries are already experimenting, trying out different solutions, and using new tools, such as 'social bonds', to build partnerships that support spending money on solutions that work.

We need to make use of the values, experiences and traditions that we have built up in our systems, and systematically eliminate the barriers that stand in the way of our enormous human capital, so that we can use it to develop and test new solutions. We also need to make use of the resources that exist in the voluntary organisations and further equip them to take on the difficult task of providing welfare services, and draw upon the valuable social networks on which the voluntary organisations are based, and the flexibility that they can contribute in developing solutions.

We must not be afraid of this challenge or feel that innovation is synonymous with turning our backs on our history. On the contrary, we should 
remember that our welfare models arose as innovative solutions to the huge challenges of the day, and still demand innovative efforts.

The first part of my report deals with proposals for ways in which we can strengthen the Nordic co-operation in the social area through more systematic co-operation in sharing and exchanging knowledge and experience, as well as how we can secure a more demand-oriented approach to the Nordic initiatives. The Nordic co-operation in the social area could deliver much more to the individual countries than is the case today, and more systematic and demand-oriented social co-operation could provide the Nordic countries with better and greater support for their national development work.

The second part of the report focuses on key themes for Nordic co-operation in the social field in the form of collaboration on social innovation, social investment and prevention, and on strengthened user focus and user involvement. Finally, proposals are presented for strengthening Nordic co-operation with voluntary organisations in the social field.

Systematic knowledge-gathering and the exchange of experience is important to secure better social initiatives, especially in relation to children and young people, vulnerable adults, people with disabilities and the elderly. In my many meetings around the countries, I have found this to be a primary concern of many of the key actors in the sector. The proposals in the first two parts of the report are aimed precisely at strengthening efforts in relation to these target groups. Nonetheless, inspired by my many visits in the countries, I have also found it necessary to propose target group-specific initiatives for Nordic co-operation. These proposals are contained in the third part of the report.
During my visits to the countries, I have become aware of the importance of viewing social initiatives in a broader perspective. In the final part of my report, I therefore propose collaborative efforts on housing and the sparsely-populated areas of the Nordic countries, as well as suggestions for international aspects of the Nordic co-operation in the social field. I have attempted to a certain extent to address education, health and working conditions in proposals aimed at individual target groups, but it is clear that these areas also play a role in social policy initiatives in general. I would therefore like to encourage the Nordic Council of Ministers for Health and Social Affairs to engage and co-operate, where relevant, with other Nordic ministerial councils when my recommendations in this report are being discussed and implemented. 


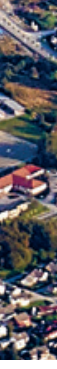
ra 70 .

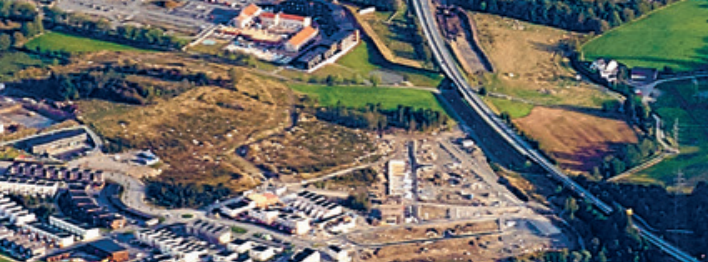

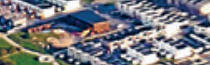

$\rightarrow$ cind

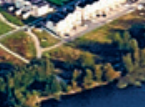

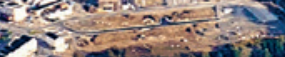

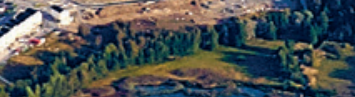

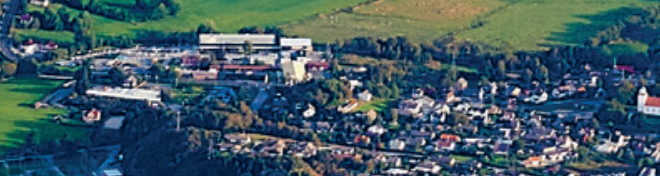

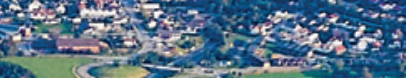

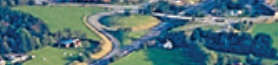




\section{Towards a more knowledge-based and demand-oriented Nordic co-operation in the social field}

This review of the Nordic co-operation in the social field has revealed that the various actors in the social field in the Nordic countries wish to strengthen Nordic co-operation on knowledge and interventions that work, and make the Nordic co-operation more demand-oriented. There is a wish that the results of the Nordic co-operation should be more applicable in the work in the social field in the Nordic countries and in the Faroe Islands, Greenland and the Åland Islands. In this connection, it is important to examine whether the organisational structures for the Nordic cooperation in the social field could better support and reinforce this wish, thereby strengthening the Nordic co-operation in social matters, to the benefit of the Nordic countries and their citizens.

The following thus presents proposals for ways in which the Nordic co-operation in the social field could be made more demand-oriented and more systematic in relation to work on knowledge and interventions that work. In this context, it is also recommended that the organisational resources available to Nordic co-operation, in the form of institutional structures, should be reviewed so they can support this work.

PROPOSAL 1: SYSTEMATIC CO-OPERATION ON KNOWLEDGE AND INITIATIVES THAT WORK IN THE SOCIAL FIELD

In all the Nordic countries there is demand for greater knowledge about what works, and for several years the countries have been working systematically to develop knowledge and test out methods in the social field. Today, however, the
Nordic co-operation provides a relatively modest and somewhat ad hoc-based contribution to the national initiatives of the various countries in relation to knowledge-based social interventions. There is huge untapped potential inherent in the Nordic co-operation in connection with knowledge in the social field, which can be released if the co-operation is more systematically utilised, and more closely linked to the countries' key actors in the field.

The Nordic co-operation in the social field should be an attractive platform for the countries' key actors, such as boards/directorates and sectoral research institutions, which they can use to exchange knowledge and discuss proposals for concrete Nordic initiatives to complement their national efforts in relation to knowledge of social interventions that work. There is for example a particular benefit in testing interventions for relatively small target groups, where the target group in each country is too small to conduct tests efficiently. Here, co-operation could provide benefits in the form of joint testing of interventions.

Nordic co-operation on knowledge about interventions that work could also usefully encompass the exchange of experience on successful implementation in practice in the social field. In directorates, authorities, research institutions and professional associations in and outside the Nordic region, a solid body of knowledge has been built up on effective implementation. In this context, attention could also be focused on how best to phase out initiatives that do not work. 
A number of different initiatives and forms of co-operation in the area could be considered:

- Relevant fora, such as the suggested Nordic Social Co-operation Forum mentioned in proposal 2, or similar high-level Nordic meetings, could be regularly informed of key initiatives in the various countries on the development and testing of specific interventions for target groups in the social field. At the same time, this could function as a platform where the countries could discuss possible Nordic initiatives to develop, test and share knowledge about interventions that could be presented to the Nordic Council of Ministers for Health and Social Affairs and the Nordic Committee of Senior Officials for Health and Social Affairs, or continue as bilateral collaborations.

- The establishment of networks for national sector research institutes and the like, which could support the establishment of joint initiatives on methodological testing, research collaboration, etc.

- Exchanges of experience and the possible development of common methods for documenting and refining promising social practice that shows potential, but which has not yet been tested and documented.

- Joint testing of interventions and joint research on the effects of interventions across the Nordic countries in order to achieve larger target groups.

- Utilisation of the Nordic co-operation as a platform for obtaining research-based knowledge from countries outside the Nordic region, including, for example, via joint Nordic funding of meta-studies on the impact of social interventions.

- Further development of the existing Nordic co-operation between internet portals that distribute knowledge in the social field to municipalities and other actors in the social field.

\section{PROPOSAL 2: A MORE KNOWLEDGE-BASED} AND DEMAND-ORIENTED CO-OPERATION

The Nordic co-operation has great potential for providing concrete contributions to the national development work of countries in the social field. However, this potential is not sufficiently utilised. There is currently no comprehensive, continuous and systematic mechanism for reviewing what the country's key actors in the social field want the Nordic co-operation to contribute. This poses the risk that the Nordic initiatives will not deliver what is needed, and that important potential for co-operation will remain unexploited.

By their nature, the Nordic initiatives cut across the public administration cultures and organisational structures of several countries. In the search for compromise, it is important to avoid ending up with products that work in a Nordic 'logic', but which are not close to the reality in which the countries work. It is therefore necessary to ensure that the products developed through the Nordic co-operation and its communications are closely linked to the national structures for the development and dissemination of knowledge in the social field.

A more demand-oriented approach, which more systematically involves key national actors, and which contributes to formulating the countries' demand for Nordic co-operation, will enhance the quality and relevance of the collaborative Nordic initiatives. Overall, the Nordic co-operation in the social field should be strengthened in terms of the identification of the demand, the design of the specific projects and expected deliveries, and the dissemination of knowledge and results. 


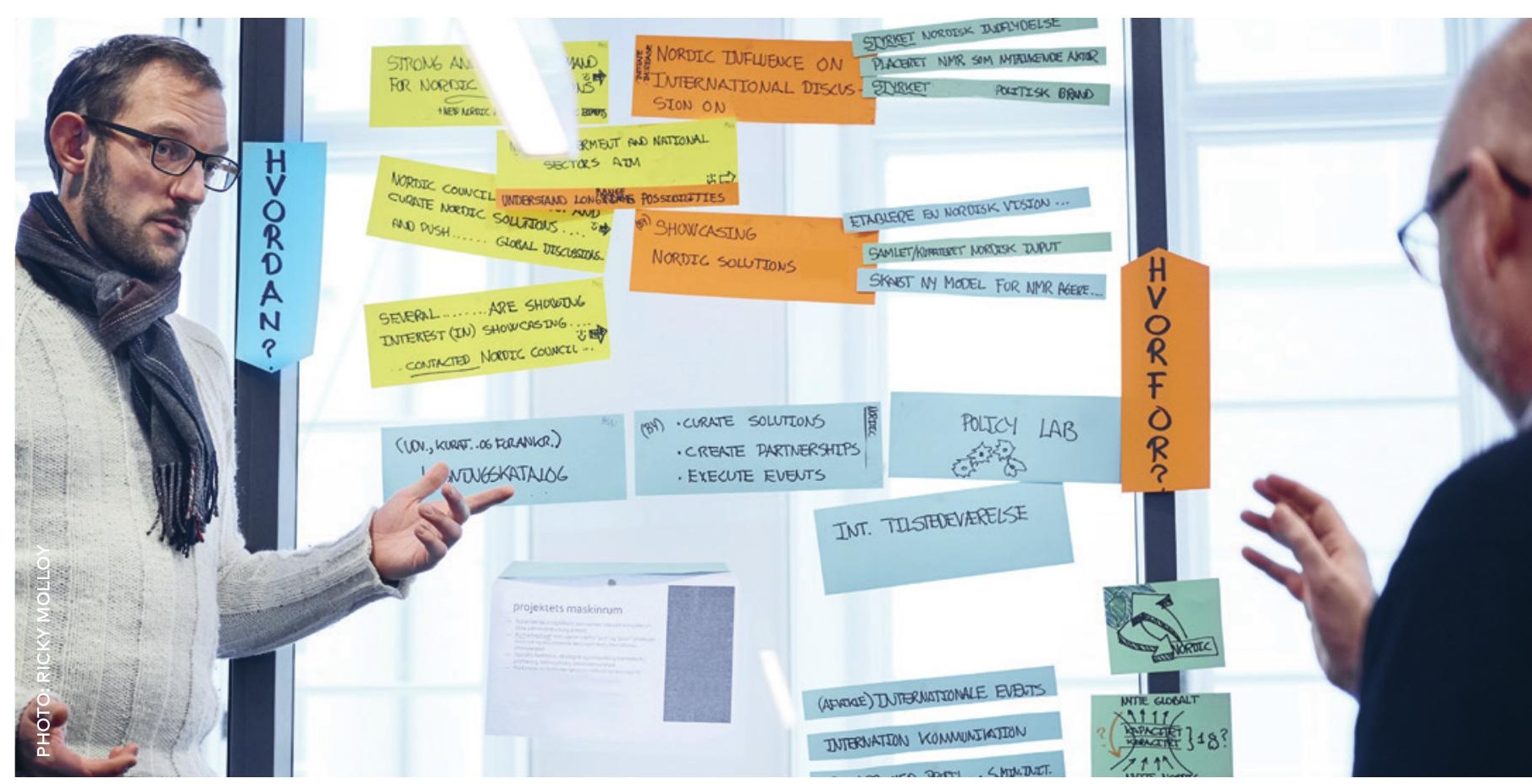

\section{Forum for Nordic co-operation in the social field}

It is proposed that a Nordic Social Co-operation Forum be established. This forum should continuously identify the countries' demand for Nordic co-operation in the social field, and on this basis formulate proposals for the consideration of the Nordic Council of Ministers for Health and Social Affairs and the Nordic Committee of Senior Officials for Health and Social Affairs on Nordic initiatives under the aegis of the Nordic Council of Ministers. The forum should have the participation of the relevant ministries and directorates from the Nordic countries as well as the Faroe Islands, Greenland and the Åland Islands. The secretariat for the forum could for example be provided by the Nordic Welfare Centre, in co-operation with the secretariat of the Nordic Council of Ministers. The Nordic Social Co-operation Forum could be supplemented as necessary by high-level meetings or the equivalent in selected sectors of the social field, such as initiatives for children.

\section{Better involvement of national actors in the design of initiatives}

It is proposed that, under the auspices of the Forum and the Nordic Committee of Senior Officials for Health and Social Affairs, discussions should take place on how better to involve relevant actors when defining specific Nordic initiatives. In this respect, better support should be provided to ensure that when a Nordic initiative is designed, a clear picture is obtained of the target group for the initiative (e.g. the directorates in the various countries), the target group's demand and the type of delivery the target group wishes, and to ensure that ownership of the initiative is achieved among the relevant actors. This should include all initiatives under the auspices of the Nordic Welfare Centre, projects initiated by the country holding the presidency for the Nordic co-operation and other initiatives in the sector that are decided by the Nordic Council Of Ministers for Health and Social Affairs/Nordic Committee of Senior Officials for Health and Social Affairs and co- 
ordinated by the secretariat of the Nordic Council of Ministers.

\section{Communication and dissemination of know- ledge from Nordic projects}

Initiatives should be implemented to ensure that the dissemination of knowledge from Nordic initiatives, including initiatives by the Nordic Welfare Centre, is more closely linked to the national dissemination of knowledge in the social field. Right from the design stage for a Nordic initiative, consideration should be given to how the results of the initiative should be included in the knowledge bases and communication channel strategies used in the countries to convey the best available evidence to municipalities, suppliers of social services and other social actors. As an example, there are central internet portals in the countries which, at the national level, convey the best available evidence in the social field, especially in the field of children and youth, to the municipalities and other actors. These include Vidensportalen in Denmark, Metodguiden in Sweden, Ungsinn in Norway and Kasvuntuki in Finland. The Nordic Committee of Senior Officials for Health and Social Affairs has already decided to support co-operation between these portals, and it may also be considered whether these and similar dissemination measures in the countries could be used more widely to disseminate knowledge from the Nordic projects.

It is also proposed that continuous assessment be undertaken concerning how knowledge products from concrete initiatives can be made more relevant to actors in the Nordic countries whose working language is not a Scandinavian language. This could for example be done by making more frequent use of translation into English. In this way, the products of Nordic co-operation in the social field could also to a greater extent be used in collaborations with actors outside the Nordic region.

\section{PROPOSAL 3: DEVELOPMENT OF ORGANISATIONAL STRUCTURES}

In order to support the implementation of the above proposals, it is important that the organisational resources available to the Nordic social co-operation in the form of institutions and cooperative bodies can contribute to more demand-oriented co-operation, focusing on knowledge of initiatives that work. It is therefore necessary to examine how the sector's two knowledge-producing and co-ordinating organisations, the Nordic Welfare Centre and the Nordic Social-Statistical Committee (NOSOSKO) can better meet the countries' expectations towards Nordic co-operation.

\section{Nordic Welfare Centre}

In a number of concrete projects, the Nordic Welfare Centre (NWC) has provided relevant and useful products and services in the form of, for example, networks and seminars. It is however assessed that the potential of the institution could be better utilised than it is today. A number of factors are relevant to take into account in relation to the further development of the NWC.

The selection of the fields in which the NWC works, as well as the design of specific projects undertaken by the NWC, is currently initiated to a relatively high degree by the NWC itself, and for historical reasons there is a special focus on some topics rather than others. In order to ensure that the work of the NWC is in harmony with the countries' current demand for Nordic initiatives, the possibility of the countries to influence the overall work of the NWC should be strengthened, and the institution's work on designing specific projects could be further developed.

It is proposed to carry out a process that will result in clearer requirements concerning which deliveries are desired from the NWC, including a 
more precise description of the roles and tasks of the institution. At the same time, it is proposed that the Nordic Committee of Senior Officials for Health and Social Affairs, the secretariat of the Nordic Council of Ministers and the leadership of the NWC together carry out a process to make the steering of NWC more transparent and efficient in delivering what the countries demand.

The countries work highly systematically to secure the knowledge base for initiatives in the social field. For example, the countries' professional boards and directorates have well-defined requirements towards when an intervention may be considered to be well-documented on the basis of research and/or well-described practice. To be a legitimate actor in this landscape, the NWC must to a greater degree ensure that its deliveries meet these requirements.

Clearer expectations could usefully be created towards the task and role of the NWC, in view of the fact that the countries possess specialised professional environments in, inter alia, boards/ directorates, research institutes and knowledge centres that can be more directly brought into play in the Nordic co-operation in the social field, for example with the NWC in an enhanced role as facilitator.

It is thus proposed that the NWC develop its products and processes to establish a stronger link with the priorities of the countries under the auspices of the Nordic Council of Ministers for Health and Social Affairs and the Nordic Committee of Senior Officials for Health and Social Affairs, as well as with the work at national level to further develop the quality of social interventions, and the national dissemination strategies and communication channels for knowledge in the social field.

\section{Nordic Social-Statistical Committee (NOSOSKO)}

NOSOSKO, the Nordic co-operation on comparative statistics, the co-ordinating body of which includes representatives from the authorities and statistical agencies of the countries, was established in 1946 and is one of the oldest forms of Nordic co-operation. Comprehensive and vital work is carried out by the committee, but potential can be seen for strengthening its relationship with the priorities of the Nordic Council of Ministers for Health and Social Affairs/Nordic Committee of Senior Officials for Health and Social Affairs and other Nordic initiatives, and the application of NOSOSKO's deliveries could also be further promoted.

It is proposed to assess whether there is a need to adjust NOSOSKO's mandate with the aim of matching NOSOSKO's production to the demand of the countries' actors regarding comparative Nordic statistics. In this context, it is worth remembering that when NOSOSKO was founded there was a strong focus on input in the welfare systems, and that NOSOSKO has, over the years, delivered a good response to this through statistics on expenditure on social benefits and social services. However, the focus of social policy today is more on the impact of the policy. It may therefore be worth considering whether NOSOSKO could contribute more to Nordic collaborations that examine the impact of social interventions and structures in the social field. At the same time, it may be examined how the work of NOSOSKO could be more closely linked to the Nordic co-operation in the social field in general, including in the form of contributions to current initiatives, as well as other Nordic statistical co-operation, such as under the auspices of Nordregio. 


\section{Key themes for Nordic co-operation in the social field}

A Nordic contribution to strengthening the knowledge base of social policy should also include the development of new ideas and the promotion of cross-sectoral initiatives to reflect the wishes and needs of the users. This chapter presents proposals to strengthen the Nordic co-operation on social affairs by focusing on social innovation and social investment in order to make our social systems more flexible and open to innovation, with a stronger focus on users. Voluntary organisations can play an important role in the development of social interventions, as they can often contribute in ways that are difficult for the public sector to implement. There are therefore also a number of proposals for ways in which voluntary organisations can be involved in Nordic initiatives in the social field.

\section{PROPOSAL 4: SOCIAL INNOVATION}

There is broad consensus among the actors in the social sector that there is a need for a stronger knowledge base for social policy and social interventions. Part of the road to this goal involves placing much more emphasis on social innovation and supporting the systematic spread of new, effective interventions. Social innovation in this context is about strengthening social interventions by developing new ideas and services that address social issues, and which are more effective than existing solutions - such as, for example, creating new social relationships or partnerships.

In recent years, significant development has taken place in the social field in the Nordic countries, with targeted and systematic work being done to develop, test and implement effective inter- ventions, and the countries have in various ways launched initiatives designed to promote social innovation.

But more remains to be done, because our structures are not always suitable for promoting social innovation and adopting new, effective solutions. On the contrary, our systems can have a built-in bias in relation to existing, publicly-produced solutions - especially if there is an overlap between the functions that define the need for a solution, prepare the solutions, administer them and evaluate the results. At the same time, strict requirements towards documenting the effects of new solutions are usually imposed, while existing solutions are not tested with the same degree of stringency. The risk is that, despite the fact that we wish to promote social innovation, we will to a large extent continue to produce what we already produce, and underestimate the need for change.

There are a number of challenges that can hinder the development of new interventions through social innovation, and which should be addressed. Amongst other things, the resources devoted to research and innovation in the social field are still more limited than in most other sectors. Moreover, many new interventions are developed on the basis of time-limited project financing, and as a result money is not set aside for sustaining and spreading the intervention after the funding expires, even if there are demonstrable positive effects.

In addition, there are examples of interesting and innovative solutions developed by social entrepreneurs and voluntary organisations that fail to 
receive the necessary support to be tested and recognised, so that they can be used outside the framework of a small pilot project. There are also examples of successful interventions that have been tested and shown to have scaling potential, but which have not been taken up by the public authorities. Even when new interventions prove to be effective, our systems can thus tend to stick to solutions that produce poorer results.

Across the world, we are seeing an increased focus on social innovation. In most of the West, greater focus was placed on social innovation after the financial crisis in order to reduce public expenditure and achieve better results for the same or fewer funds. In other parts of the world, the driving force behind social innovation is the increasing economic strength of countries that are experiencing growing prosperity and rising welfare needs. The interesting aspect of the latter examples is that these countries, unlike those of the Nordic region, are not blessed - or burdened with existing structures to deliver social services. As a result, they have greater freedom to think the unthinkable and to find new and innovative ways to handle new challenges.

In the light of this, we need to provide the skilled and experienced people working in the social field with better possibilities to come up with new ideas and try different solutions. Social innovation must become an integral part of our work, just as innovation is in many other parts of our economy. The Nordic countries are justifiably proud of their welfare models; these arose as innovative projects, and will require ongoing innovation if they are to remain strong and relevant to the world around us.

It is proposed that the Nordic co-operation should foster innovation in the social area through:

- A collaboration between the Nordic Council of Ministers for Health and Social Affairs and the Nordic Council of Ministers for Sustainable Growth on how to use existing innovation structures in the respective countries, together with the Nordic institution Nordic Innovation, to effectively encourage and support innovation in the social field.

- The establishment of a Nordic prize for social innovation, for example by co-operating with the Nordic Council to establish a Nordic Social Innovation Prize, to be awarded annually together with the other Nordic prizes for literature, music, film and the environment. The prize would:

- Give municipalities and other actors responsible for service provision in the social field in the Nordic region a forum where they can see the best solutions that have been developed, and use these for inspiration.

- Provide a valuable opportunity to showcase our most innovative solutions, thereby enabling public organisations and philanthropic foundations to support further development and, perhaps later, promote exports of new solutions.

- Make social innovation more visible and make it clear to the rest of the world that the Nordic countries are committed to developing the Nordic welfare model and maintaining their strong position in international comparison.

\section{PROPOSAL 5: SOCIAL INVESTMENT AND PREVENTION}

Our systems do not always possess the necessary models or incentives to encourage long-term investments in social policy solutions - rather the contrary. There are many different actors who must contribute to effective solutions, and their efforts are not always co-ordinated or adequately focused on the needs of users. Administrative 'silo' structures are a common challenge in all of the countries, and often lead to difficulties in working with solutions between these silos. 
We do not adequately recognise the need to invest in social interventions. This may be because we have not sufficiently documented the extent to which effective social intervention early in the life of the individual can produce savings later. It is relatively easy to measure an increase in the number of operations in a hospital, and the resulting drop in waiting lists, or in the number of days that patients are hospitalised while waiting for an operation. There are summaries that make it possible to compare the cost per student of various study programmes in the Nordic countries, the cost of various hospital treatments, the price of building a new apartment, and what it costs to give a person further education. On the other hand, it can be harder to win political and administrative understanding when it comes to investing in solutions that in the long term can reduce the marginalisation of adults or keep children and young people in activity and prevent them from experiencing psychological problems or abuse. Moreover, success in the social field is generally measured over a relatively short term, while solutions to today's complex societal challenges require targeted solutions that may only produce results in several years' time. In this context, it is interesting to note that in work with developing countries, there is a recognition that success must be measured on a completely different timescale - such as 4-7 years - which is far better suited to assessing the success of social interventions.

It is also important that our incentive structures create pressure on the various actors to contribute to solutions. If our health, education, housing and labour market systems worked perfectly, we would have fewer social policy challenges. Often, there is insufficient financial incentive for institutions within these areas to offer targeted support. When a person in need of support drops out of the school system, the school saves resources. When an unemployed person is considered to be no longer fit for work and is transferred from unemployment benefit to early retirement, it saves money for the system that pays the unemployment benefits. But the total cost to society of social exclusion is not necessarily taken into account. In addition, there can be a tendency for the people that fit the solutions to be offered them, which thereby ensures that targets can be reached, while people with different needs lose out. This point is further discussed under proposal 6 on user focus.

The Nordic countries, which generally provide effective solutions within the various sectors, could do much more to create coherence between the efforts of the various sectors for citizens who also have a need for social support. This is a perception shared by stakeholders across all of the countries. The incentive structure must be targeted so that different welfare areas can co-operate to solve complex problems. If an individual needs support from several different sector areas, there is a lack of co-ordinated, targeted actions to help the person get back on track.

The problem becomes even more exacerbated when those who can actually help to promote success by intervening in time are not generally the ones who can save money by doing so. In many cases, the social authorities of the municipalities are those best positioned to initiate early preventive efforts. The savings thus achieved do not always figure in the municipal budget in the social field, but in other sectoral budgets, or in the regional or state budget. Why should municipal social services use their scarce resources to invest in developing and delivering solutions to problems that are not ultimately their financial headache?

In many of the Nordic countries, there are examples of innovative attempts to solve this problem. The new Socio-economic Investment Model (SØM) 
recently developed and launched in Denmark provides for the possibility of addressing the problem, as does the Ideas for Life model used by Skandia Idéer för livet in Sweden, and initiatives in the Finnish innovation centre, Sitra. The Danish establishment of a Social Investment Foundation is another example. Solutions are also sought all over the world. Through Social Impact Bonds, for example, an economic instrument has been developed to encourage private investors to provide funding. In the Nordic region, there should be a much stronger, targeted focus on these issues.

It is therefore proposed that the Nordic Council of Ministers for Health and Social Affairs should discuss different models for incentive structures that will promote investments in early, preventive social interventions, possibly with the involvement of Nordic Council of Ministers for Finance. The discussions in the Nordic Council of Ministers for Health and Social Affairs could encompass:

- Exchanges of experience on the establishment of mechanisms to promote social investments. Inspiration for this can be found in the previously-mentioned examples, or in Nordic projects. A social investment project could be designed in such a way as to ensure that both municipalities and voluntary organisations can contribute their experience in developing solutions that are resource-efficient in relation to public budgets, and which recognise voluntary organisations as reliable and competent partners. It is also important to examine the structure of funding in the areas of education, health, housing and the labour market. It should not be 'expensive' to deliver solutions and 'free' to avoid contributing to solutions. Institutions should have an economic incentive to fight social isolation and develop individualised solutions, and it should cost them something if they fail to contribute.
- In addition, it is proposed that Nordic cooperative initiatives should be developed on methods to measure the costs and the longterm, preventive social and economic impact of early social intervention. A starting-point could be taken in the many existing initiatives in the countries.

\section{PROPOSAL 6: SOCIAL INTERVENTIONS FOCUSING ON THE USER}

Today, the individual can experience the social system and the rules in the social area as perplexing and complex, and the system as not centred on the citizen, but more producer-oriented and structured around the service providers. Silo divisions between the sectors contribute to a lack of co-ordination between the offers of the various authorities to the same citizen. Overall, this can lead to the service offers becoming standard solutions that do not adequately take account of the need for individualised solutions. People with complex problems often move between several sectors in the public system, involving multiple case handlers and action plans, which makes it difficult to develop a comprehensive effort that could potentially help the person concerned. In this regard, reference is made to the discussion under proposal 4 on social innovation, and under proposal 5 on social investment.

Let us take the typical example of a young person who is neither in work nor in education/training. Passivity often leads to a worsening of mental problems or abuse. This in turn can lead to housing problems, making it harder to find a solution to a situation of homelessness. Where do we begin? Can we offer abuse treatment without providing sufficient individual support and the prospect of a suitable education that leads to the development of skills and subsequent employment? And when should we address the housing problem? Can a homeless person be expected to put his or 
her substance abuse behind if there is no prospect of housing, work or appropriate education or training? Problems like this can be difficult to solve in all of the Nordic countries. This is partly due to the fact that all of the involved actors need to take account of short-term budgets and meet short-term performance goals, even though a long-term timescale and more co-ordinated solutions for the individual citizen would produce a better result. Moreover, lack of success in the efforts towards an individual can have very high costs for society if it leads to further mental and physical problems, lifelong welfare dependency and the corresponding loss of tax revenue. The problem is further exacerbated when we take into account the fact that these social challenges are likely to be passed on to the next generation.

However, there is now a focus on the need of social services to take greater account of the user, and the user's wishes and perspective. In recent decades, we have for example made great progress in providing services to people with disabilities, and today no-one would consider offering the same low degree of user influence on services and assistance as was the case thirty years ago. But although we have come a long way, we can still become much better at involving user groups - for example in relation to the elderly, children, the homeless, and young people without education or jobs.

In this context, voluntary organisations play an important role. There are many good examples of voluntary organisations that can provide valuable social interventions in a flexible and user-adapted manner. Voluntary organisations are better positioned than public sector organisations to build up and draw upon social networks, and can often offer solutions that are better tailored to the needs of the individual.
A clear user focus is an essential prerequisite for providing social services that meet citizens' needs and expectations, as well as being of central importance from a rights perspective. At the same time, there is a great innovative potential inherent in incorporating the perspectives and resources of individuals and user organisations in the implementation and development of social interventions.

The Nordic co-operation in the social field could provide a framework for sharing and developing knowledge that the countries can use to reinforce their national development work in bringing individuals into focus in social services, drawing upon individuals' experiences and resources. It is proposed that Nordic initiatives be launched to develop different aspects of user focus and involvement, for example:

- The development of user-adapted services, with a focus on greater user influence in the choice of offers.

- Better involvement of the individuals' perspective in their own cases and official decisions

- Organisation of user-centred social services for the elderly, people with disabilities, vulnerable adults and children and adolescents.

\section{PROPOSAL 7: VOLUNTARY ORGANISATIONS}

The Nordic countries and the Nordic governmental co-operation have a long tradition of close links with civil society. A strong and vital civil society is a cornerstone of Nordic democracy, and plays an important role in enabling Nordic citizens to channel their voices and interests outside of the political organisations. The Nordic co-operation is built upon its roots in the Nordic popular movements.

Civil society contributes to the development of the Nordic societies by involving people and creating participatory processes for their citizens, 


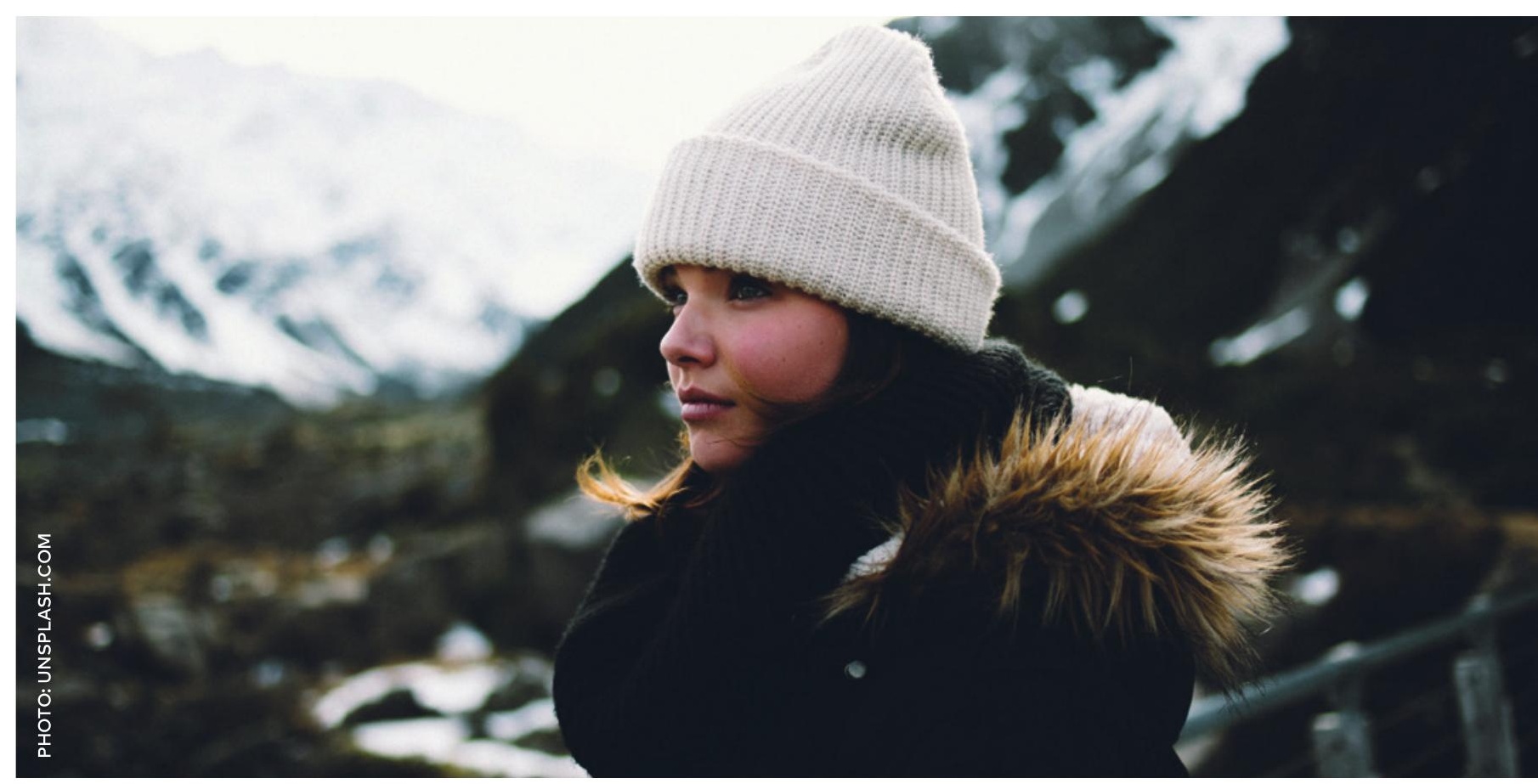

and by contributing knowledge and expertise. Several voluntary social organisations are also important providers of social services in Nordic welfare societies, and possess great potential for creating networks and social capital. Many voluntary organisations thus contribute services to people in vulnerable situations that the public sector cannot supply in the same way. These organisations can also represent people in dealing with the public authorities who supply most of the services to the individual, and many of them can also more easily construct customised solutions than the public sector, as there is greater flexibility in the individual organisation.

When we look more closely at the social problems that are most important today, loneliness, a lack of social networks and a lack of role models are some of the frequent themes. There are many advantages to the public social services, but they are inadequate when it comes to creating social networks and personal contact. Systematic efforts should therefore be made to strengthen all of the social networks in our society: family, friends, peer support, neighbourhood communities and voluntary work.

There are some excellent examples in Nordic countries of citizen initiatives that bridge the public sector's social services through networks of volunteers and users, or through a combination of volunteers, professionals and users. These are some of the many good examples of social innovation we find in the Nordic countries. It is very important to use the innovative potential of civil society to contribute to the development and delivery of flexible, citizen-oriented social interventions, and thereby contribute to the development of knowledge and good practice in the social field.

The voluntary organisations do not always have the same administrative structures as public institutions. Examples from the Nordic countries, however, show that civil society can be 


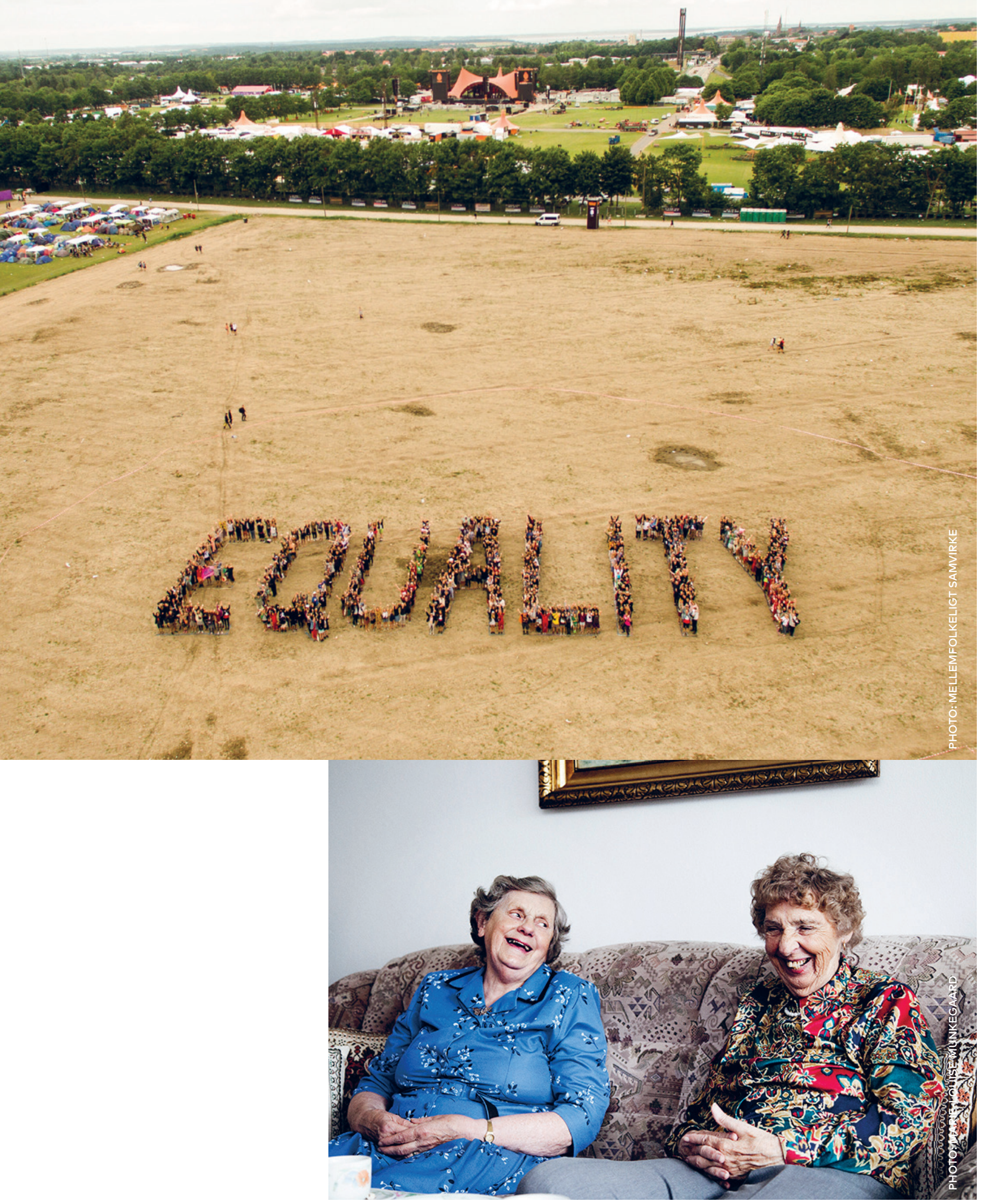


entrusted with complex and ambitious tasks, and can achieve results that would not otherwise have been possible. It is consequently important to exchange good practice experience on how to enter into contracts with civil society organisations, entrust them with important and ambitious tasks, reward them in a reasonable manner, and provide realistic reporting requirements that focus on results rather than formalities.

The impression is that there are large differences in the ways that the Nordic countries' voluntary organisations maintain contacts with each other and exchange experience and knowledge across national borders in the Nordic region. An important aspect of this is the resources that are required to participate in such international co-operation.

In the Nordic countries, strategies and initiatives have been developed to promote co-operation with civil society, prioritise the development of active citizenship and civil society, and support the knowledge and practice of the voluntary sector in the social field. A Nordic effort in the field should complement national initiatives and strengthen the voluntary organisations of the Nordic countries in partnerships that can also help to raise awareness of Nordic points of view and experience in initiatives outside the Nordic region.
It is therefore proposed that:

- The Nordic countries should launch initiatives to exchange experience about involving voluntary organisations in the development and delivery of welfare services, as well as on the impact of this on the quality of the services, and good models for ways in which voluntary organisations can obtain better access to providing and be encouraged to provide welfare services or supplement the public services. A Nordic partnership could also focus on how to involve more citizens in voluntary work.

- The Nordic countries should provide a pool to which voluntary organisations can apply for funding, for example for networking meetings with a view to enhancing the exchange of experience between the Nordic countries' voluntary organisations, or to promote a Nordic voice in international contexts and participate in conferences in the Nordic countries organised by other voluntary organisations. 


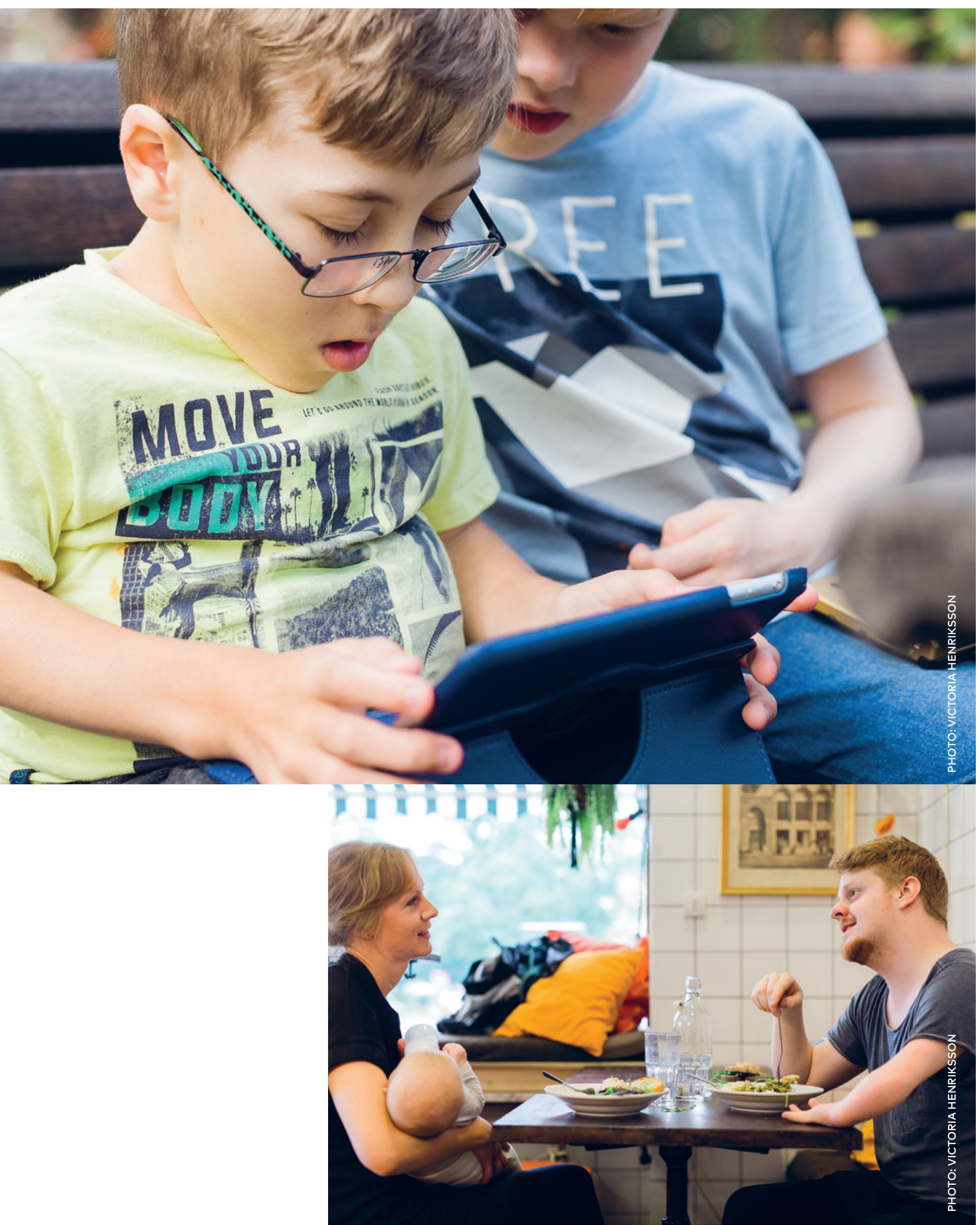




\section{Strengthened Nordic co-operation on children and young people, vulnerable adults, the elderly and people with disabilities}

The fundamental purpose of a more demanddriven and strengthened Nordic co-operation in the social field, focusing on knowledge and interventions that work, is to help to strengthen efforts for the primary target groups in the social field, i.e. vulnerable children and young people, vulnerable adults, the elderly and people with disabilities. In connection with the preparation of this report and visits to the Nordic countries, several proposals have emerged for Nordic initiatives aimed at these target groups. It is absolutely certain that there is great preventive potential in developing effective early interventions for children and young people. At the same time, demographic displacements between countryside and urban areas, the decline in the number of unskilled jobs, and a tendency towards increased problems in childhood and adolescence are bringing about a risk of increased marginalisation in society and greater social vulnerability. The demographic trends in the Nordic region also mean that there will be relatively larger group of elderly people in the Nordic region who may be in need of care. This places the welfare systems of the Nordic countries under pressure. Even though there is a well-established co-operation under the aegis of the Nordic Council of Ministers in the area of disability, greater efforts can still be made in this field.

In the following, recommendations on ways to strengthen Nordic co-operation on vulnerable children and young people, vulnerable adults, the elderly and people with disabilities are therefore provided.

\section{PROPOSAL 8: VULNERABLE CHILDREN AND YOUNG PEOPLE}

The Nordic countries have sought to provide the possibilities for a good childhood that transitions into youth in which young men and women are equipped to continue their personal development and their development as citizens. Political priorities, skilled professionals, schools and kindergartens, the efforts of voluntary organisations and, above all, the parents, children and young people themselves have in combination created a space where there can be a focus on children's rights, well-being and development opportunities.

Although the welfare services offered to children and young people in the Nordic countries are generally of high quality, there are issues that require greater efforts. Consequently, the Nordic countries are continuously implementing extensive development work to strengthen their services for children and young people and to address current challenges. In the Nordic countries extensive work of knowledge-building has been carried out on the target groups and their needs, as well as on effective methods and interventions.

Various sectors of the Nordic co-operation, including the social and health sector, the education sector and the Nordic Children's and Youth Committee (NORDBUK), have implemented a number of initiatives for children and young people. However, there remains an untapped potential for greater use of the Nordic cooperation in the social sector, as an arena in which the key actors in the Nordic countries, particularly boards/directorates and sector research institutes, can identify and initiate 
relevant co-operative initiatives as needed. These might for example encompass the exchange of knowledge and experience through networks in selected areas, but the possibilities for joint initiatives for the development of knowledge and testing of methods should also be investigated.

Below, three themes are proposed as a basis for further development of Nordic co-operation on children and youth in the social field. With a view to identifying relevant Nordic initiatives, it is proposed that further work be carried out with these and possibly other themes under the auspices of the proposed Nordic Social Cooperation Forum (see proposal 2), or another forum with representation from the Nordic countries.

\section{Children's rights}

The social authorities in the Nordic countries work extensively to help vulnerable children, but the involvement of children, enabling children's wishes and views to be included in decisions regarding their well-being, could still be strengthened. It is important to continue capacity building in this area to secure the rights of every child, and to offer the child the best possible help.

It is therefore proposed that, on the basis of the UN Convention on the Rights of the Child, Nordic initiatives should be launched to investigate how the authorities can better involve children and hear their points of view on their own cases. The informal network of child ombudsman functions in the Nordic countries could for example be involved with a view to identifying topics where Nordic initiatives could contribute to national efforts.

\section{Knowledge of what works in interventions for children}

The efforts of the Nordic countries on behalf of vulnerable children have in recent years been characterised by comprehensive knowledge-gathering in relation to effective methods for children and families in need of support. As suggested in proposal 1 on systematic co-operation on knowledge and interventions that work in the social field, the Nordic co-operation could to a greater extent function as a platform where countries can exchange knowledge of effective interventions, and could also potentially provide a platform for exploring the possibilities of conducting joint trials of methods and research projects. Implementing joint Nordic initiatives on methods testing is ambitious and will require political prioritisation and co-ordination of resources - not only in the Nordic budget, but also within the countries themselves.

It could therefore be considered whether co-operation in the field of children and youth could be strengthened by setting up a high-level meeting or the like at which the relevant directorates in the countries could meet and discuss themes and specific Nordic initiatives for children and young people. Such a forum could for example discuss, on an ongoing basis, the possibilities for joint Nordic testing of methods, and exchange information on current national initiatives. This should be co-ordinated in relation to the existing Nordic initiative on disseminating knowledge on the field of children and youth via internet portals, as initiated by the Nordic Committee of Senior Officials for Health and Social Affairs in 2018, and which is managed as a project by the Norwegian Directorate for Children, Youth and Family Affairs.

\section{Young people suffering from social exclusion}

In the Nordic countries there is a growing group of young men and women who are struggling with mental health problems. Many young people are neither in active education nor on the labour market, and are at risk of developing long-term social exclusion, which often gives rise to a number of social and health problems that can extend far into adulthood. The Nordic co-operation could systematically exchange experiences and develop knowledge about, inter alia: 
- National strategies to prevent the marginalisation of young people, including information on large-scale initiatives and research projects that could be relevant across national borders.

- Easily-accessible counselling services for young people, where young people can quickly obtain help. In this context, experience of co-operation with voluntary organisations on relevant advisory services for young people could also be examined, as well as cross-sectoral initiatives that co-ordinate interventions from different sectors (e.g. the social, educational and psychiatric sectors) for young people with complex support needs.

- Cross-sectoral incentive structures that promote early preventive efforts for young people and prevent individual cases falling between two stools - see proposal 5 on social investment and prevention.

- Focus on and involvement of young people's views in the development of interventions and services in the field. Co-operation could for example be built with initiatives such as the Nordic Youth Summit, focusing on young people's mental health, which was held in Copenhagen in November 2017 with voluntary organisations from the Nordic countries who work with mental health among young people.

- Exchanges of experience on efforts to promote the inclusion of young men and women in education and the labour market in sparsely-populated areas (see also proposal 13 on sparsely-populated areas).

\section{PROPOSAL 9: VULNERABLE ADULTS}

Help and support for citizens in vulnerable social situations is one of the cornerstones of the Nordic welfare societies. This applies both to those who need help from society for a short period of time, and to those who for various reasons require social support for a large part of their lives. The Nordic co-operation should contribute to the development of knowledge and the exchange of experi- ence in this area, but also create platforms for ongoing discussions on how the welfare society can be organised to provide valuable support to those in need.

Involvement in the labour market is the focal point for a number of efforts for people in socially vulnerable situations. Participation in the labour market helps to secure self-determination and self-esteem, and is an important source of access to networks and participation in society. But in all of the countries there are groups of people who, despite many different efforts, do not enter employment. This also applies to refugees and immigrants. An important task for social policy initiatives is therefore to counter the marginalisation of those who have a long path to the labour market. This task has a significant gender dimension in the Nordic societies, where women are increasingly better educated than men, while the number of unskilled jobs is reducing. A cross-sectoral approach in co-operation with the gender equality and employment sectors of the Nordic co-operation could be an interesting starting-point for the identification of relevant Nordic co-operation initiatives on the conditions of vulnerable men with regard to participation in society and the labour market. Similarly, contributions to the existing Nordic co-operation on integration, which the Nordic co-operation ministers have initiated, could be relevant in focusing on preventing social vulnerability among newcomers who have not yet gained a foothold in the Nordic societies.

It is important that people in a socially vulnerable situation have a strong voice in the discussion and design of the social policy initiatives that involve them. The voluntary organisations perform an important task here, and this is work that could be usefully promoted through the Nordic co-operation. The voluntary organisations in the Nordic countries with vulnerable adults as their 
target group co-operate to varying degrees - for example in the European Anti-Poverty Network. But Nordic and international co-operation demands resources, and it can be challenging for organisations to find the necessary funds to participate. The proposed funding pool to support Nordic co-operation between voluntary organisations included in proposal 7 would be capable of supporting the co-operation of civil society across the Nordic region in the area of vulnerable adults.

Nordic co-operation to strengthen efforts for the socially vulnerable and prevent marginalisation should also be seen in conjunction with a number of the other proposals in this report. Two of the suggested themes in the proposed co-operation on housing and social policy contained in proposal 12 are housing for the socially vulnerable and homeless, and social housing efforts in municipal housing and co-operative housing. Moreover, the development of knowledge on effective interventions for the socially vulnerable should be boosted in an enhanced Nordic co-operation on knowledge, as described in proposal 1. The OECD's project on "Faces of Joblessness: Understanding employment barriers to inform policy", as mentioned in proposal 14 on international co-operation, could also be relevant as an inspiration for the work of the Nordic co-operation with vulnerable adults and their connection to the labour market.

\section{PROPOSAL 10: ELDERLY}

Citizens in the Nordic region are living longer, which means that the proportion of elderly people is rising. In a global perspective, lifespans are relatively long in the Nordic region, and are above the average for both the EU and the United States. Although many older people are healthy and manage well, and despite the fact that longer lifespans are a positive development, it also poses some challenges, as social spending on care of the elderly rises. In the longer term, more elderly people will need help and care. The focus is thus on resources for elderly care, alternative ways of organising care and the quality of this, and the recruitment of care staff to work in the elderly sector when there are more elderly people, and fewer of them are in the workforce.

The demographic development also means that as more and more people move to the larger cities in the Nordic region, it is the older population that remains behind. This poses a challenge in relation to organising good and efficient care, as well as a risk of greater loneliness and isolation from society when many people move away. Consequently, the area of the elderly is also relevant to the proposed co-operation included in proposal 13 on sparsely-populated areas.

All of the Nordic countries face the same challenges in this field. It would therefore clearly be beneficial to increase co-operation on the challenges of the care for the elderly in relation to better quality and the use of rehabilitation, the use of welfare technology and the issue of recruiting staff for the elderly sector in future.

The area of the elderly is in focus both within and outside the EU. One of many examples is the WHO network Age-friendly cities and communities, in which cities in the Nordic countries participate. In many ways, the Nordic region is on top when it comes to the elderly - both in terms of care, welfare technology and inclusion. However, there remains considerable potential in the Nordic region to develop the area further, both within the Nordic region and internationally.

The Nordic Council of Ministers for Health and Social Affairs has chosen to prioritise the area as a political theme for 2019-2021 under the heading "How do we create more cohesive care processes, with particular focus on older users and patients?" The Nordic co-operation also operates several activities with relevance for elderly people, such as 


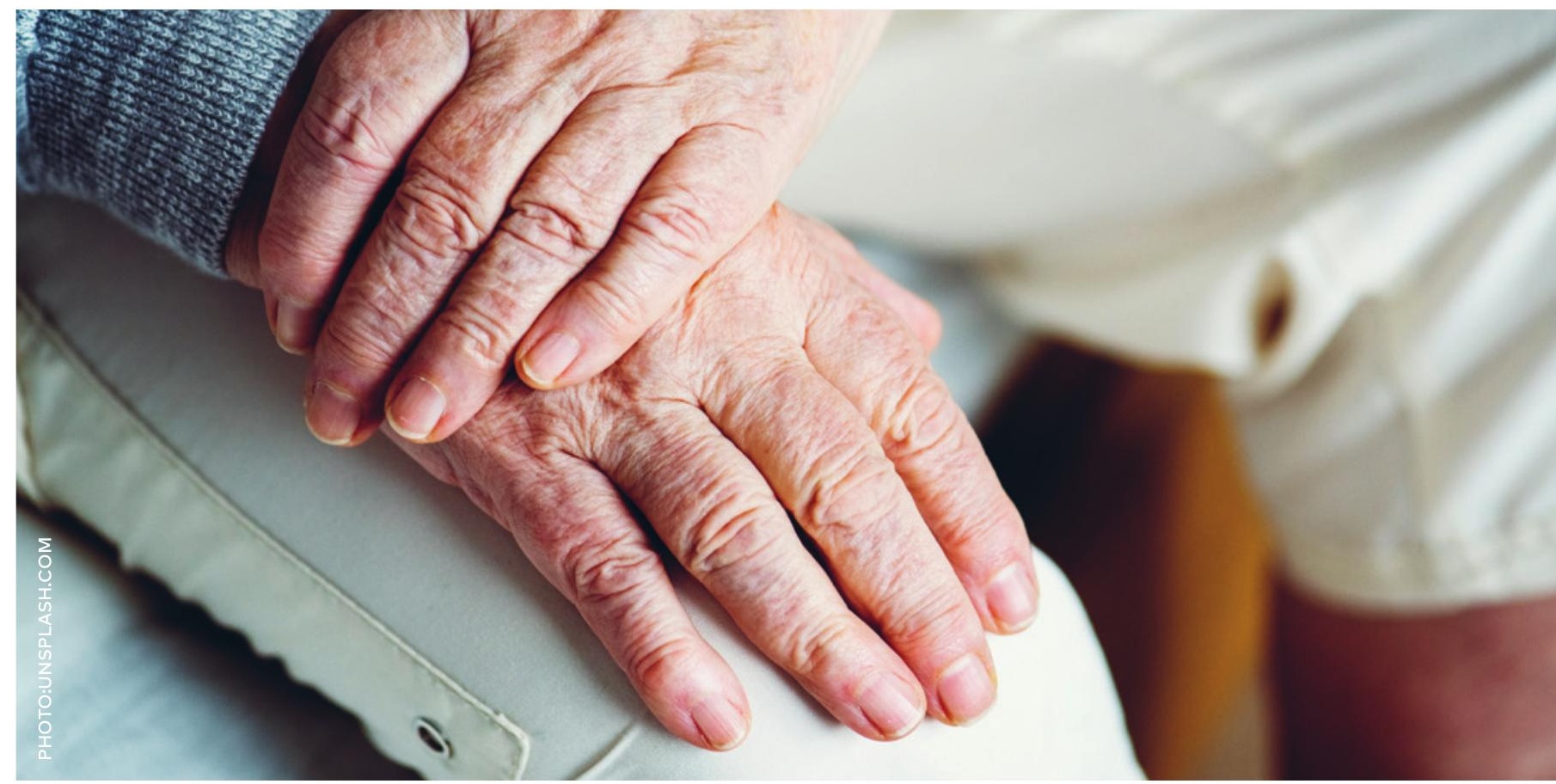

welfare technology, Nordic dementia networks and the development of elderly-friendly communities. It is important that this work is maintained, strengthened and further developed in the Nordic region, so that the Nordic co-operation can help to meet the challenges of demographic change and the consequent rise in the number of elderly people.

It is proposed that the Nordic Council of Ministers for Health and Social Affairs should consider how the existing Nordic co-operation in the field of the elderly could be further developed to include relevant new themes.

In the Nordic countries there is a great deal of focus on rehabilitation and efforts aimed at allowing older people to maintain an independent, meaningful and self-reliant life, with a holistic view of the life situations of elderly people. It is therefore proposed that the Nordic co-operation should focus on knowledge-sharing and the exchange of experience between countries in relation to rehabilitation for the elderly.
With regard to housing for the elderly, it would be interesting in a Nordic perspective to examine the possibility of providing more flexible forms of housing for the elderly and their needs. Intensified Nordic co-operation on housing, as suggested in proposal 12, could also aim to make it more attractive to build affordable housing for various target groups, including the elderly.

It is also proposed that a joint Nordic initiative be established for the exchange of knowledge and experience in effective national and local initiatives to recruit staff to the care sector, including ideas for new initiatives. Special attention could be paid to improving the qualifications of employees and retaining employees in rural districts, and ways to recruit more men to the care sector. In this regard, consideration should be given to the organisation of the work in elderly care, including how to make elderly care more attractive as a workplace for both men and women. 


\section{PROPOSAL 11: DISABILITY}

Nordic co-operation in the area of the disabled is well-functioning and relatively comprehensive, and primarily consists of three tools: the Council for Nordic Co-operation on Disability, which is an advisory body for the entire official Nordic co-operation, the cross-sectoral disability action plan of the Nordic Council of Ministers focusing on human rights, sustainable development and freedom of movement, and the Nordic Welfare Centre, which functions as secretariat for the Council for Nordic Co-operation on Disability, and which in addition administers a support scheme that promotes Nordic co-operation between disability organisations.

Disability policy contributes to a sustainable society in which no one is left outside, with the goal of including people with disabilities in all areas of society. The demographic trends, with an aging population in the Nordic region, also mean that there are more elderly people with disabilities. Policies on disability are increasingly influenced by the rights perspective, which has acquired global expression in the UN Convention on the Rights of Persons with Disabilities, UNCRPD. All of the countries in the Nordic region have ratified the convention.

\section{Accessibility}

A key element in promoting the inclusion of people with disabilities is the work to improve accessibility in society. The Nordic co-operation can complement the national work in the field by building on the work already carried out in relation to the Council for Nordic Co-operation on Disability. The collaboration will require efforts from several policy sectors. Three aspects of accessibility and user involvement may be identified that would be relevant to enhanced Nordic cooperation in this area:

\section{Accessibility in relation to housing}

The home is of great importance to the life and well-being of the individual. For individuals with a disability it is particularly important that one's own home is accessible, but accessibility is also important in relation to other people's homes and public buildings. Proposal 12 on housing and social policy also incorporates this aspect in the wish for greater Nordic co-operation in housing - for example in relation to standards for accessibility and universal design, and in housing for people with disabilities.

Labour market attachment Although they wish to work, persons with disabilities often find it harder to gain a foothold in the labour market and thereby participate in working life. In co-operation with the labour market sector, it should therefore be discussed how to create initiatives that will secure employment for more people with disabilities. New technological possibilities and solutions can make an important contribution in this respect.

The involvement of voluntary organisations in work with accessibility Voluntary organisations, with their expertise and experience, play an important role in building up a society that is accessible to all, and they can also act as advocates for people with disabilities. It is therefore important that these organisations participate in Nordic co-operation projects in this area. Reference is made here to proposals 6 and 7 regarding the strengthening of user focus and Nordic co-operation in relation to voluntary organisations.

\section{Rare disabilities}

There has been good experience in cross-border co-operation regarding rare disabilities. The Nordic countries co-operate under the auspices of the EU, and the Nordic Council of Ministers has established a Nordic Network on Rare Diseases, which encompasses social and healthcare initiatives and 

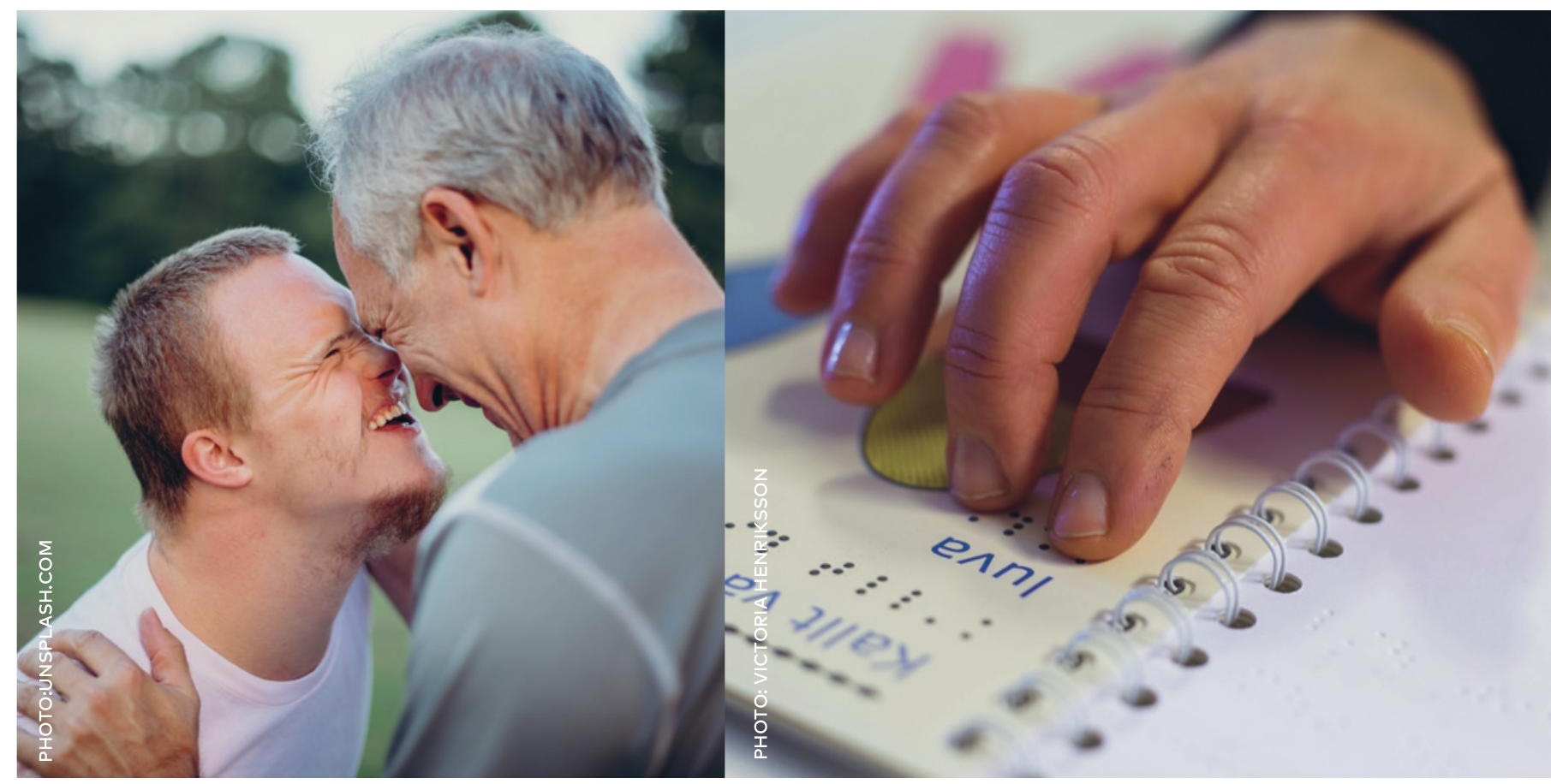

involves authorities, competence centres and user organisations.

Given that the target groups are small in the field of rare disabilities, the 'economies of scale' that can be achieved by establishing common Nordic initiatives can be great in terms of the ability to develop knowledge and create networks of specialists and professionals across the borders of the Nordic countries. A good example of this is the Nordic co-operation on deaf-blindness, which is supported by the Nordic Welfare Centre. In the light of proposal 1 on systematic co-operation on knowledge in the social field, it is proposed to examine how the Nordic co-operation could more closely co-ordinate systematic collaboration in developing knowledge in the area of rare disabilities, including through the facilitation of co-operation between specialists in the various countries. An important group in this context is children with rare disabilities. A new Nordic initiative should be co-ordinated in relation to the existing Nordic Network on Rare Diseases.

\section{Education}

One focus area in the Action Plan for Nordic Co-operation on disability 2018 to 2022 is on initiatives that could strengthen knowledge and dialogue on human rights. In extension of this, it is proposed that the possibilities for Nordic co-operation on education in relation to the area of disability should be more closely examined. There are already considerations in this regard under the aegis of the Council for Nordic Co-operation on Disability, including in relation to the Nordplus and Nordic Master programmes. In order to promote these considerations, it is proposed that a Nordic seminar be held with relevant stakeholders from the educational institutions and the disability area, to discuss the need for closer educational co-operation in the field of the disabled in the Nordic region. 

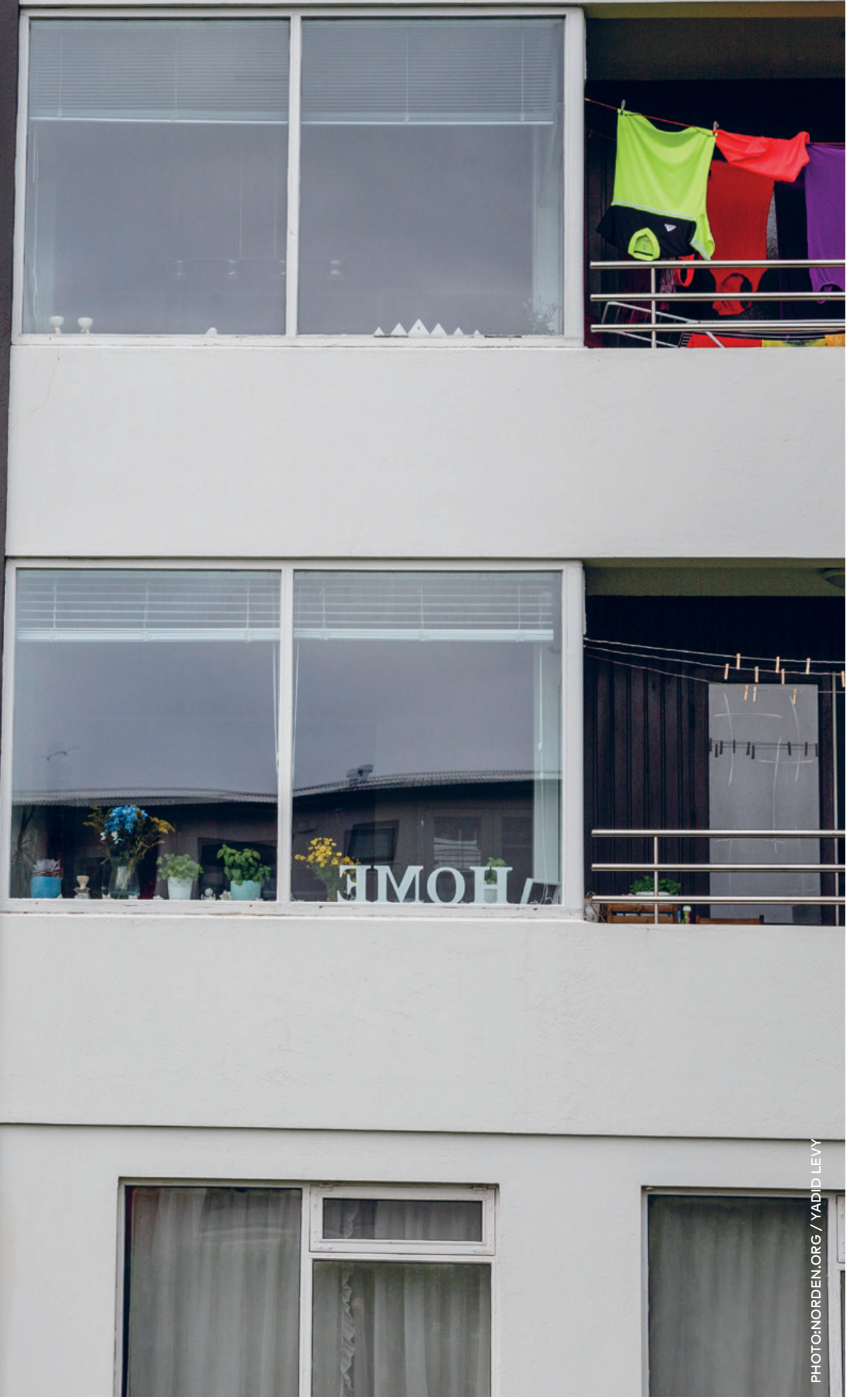


\section{Social initiatives in a broader perspective}

During visits to the Nordic countries in connection with the preparation of this report, it was repeatedly mentioned that both housing and the Nordic geography with its many sparsely-populated regions create particular social challenges. In the housing sector, the Nordic countries are currently experiencing rising house prices, especially in urban areas, which makes it difficult for many people to find affordable housing, and there is not always the necessary flexibility in the forms of available housing, for example in housing for the elderly, or for people with disabilities. The Nordic region is geographically large, with many sparsely-populated areas. As in many other countries outside the Nordic region, several of these areas are experiencing the migration of people into more urban areas. This presents challenges in terms of maintaining a high level of social services in the more thinly-populated areas.

This part of the report therefore contains proposals for strengthening the Nordic co-operation in the areas of housing and social services, as well as for strengthening the Nordic co-operation in the special social issues associated with areas with a low population density.

Many countries outside the Nordic region look to the Nordic welfare model and Nordic welfare solutions to obtain inspiration for new social solutions. But the Nordic countries can also obtain new knowledge from outside the region. The profiling of the Nordic region and Nordic welfare solutions outside the Nordic countries and in various international fora is about drawing attention to the Nordic welfare model and gaining knowledge and inspiration from different models elsewhere. Consequently, this part concludes with proposals to strengthen the Nordic co-operation in the international field.

\section{PROPOSAL 12: HOUSING AND SOCIAL POLICY}

The home is an essential part of the framework of every individual's life and access to suitable accommodation is of great importance to the individual's well-being and possibility of participating in society. This applies to everyone, and in particular to people with special support needs, such as the elderly, people with disabilities and vulnerable groups, who often have special needs in relation to housing.

The tendency in all of the Nordic countries is that it has become more difficult to find an affordable home in the cities. Some cities, particularly the capitals, are experiencing a housing shortage. Targeted urban development and gentrification has made many urban environments more inviting, but the flipside of the coin is often that an increasing proportion of the housing available to people with low or moderate incomes has been rebuilt or renovated, with the result that people with lower or moderate incomes can no longer afford it.

Housing conditions and housing policies are highly relevant in the overall context of social policy. Despite this, housing policy co-operation under the auspices of the Nordic Council of Ministers has been largely absent, and there is untapped potential for collaboration on, for example, exchanges of 


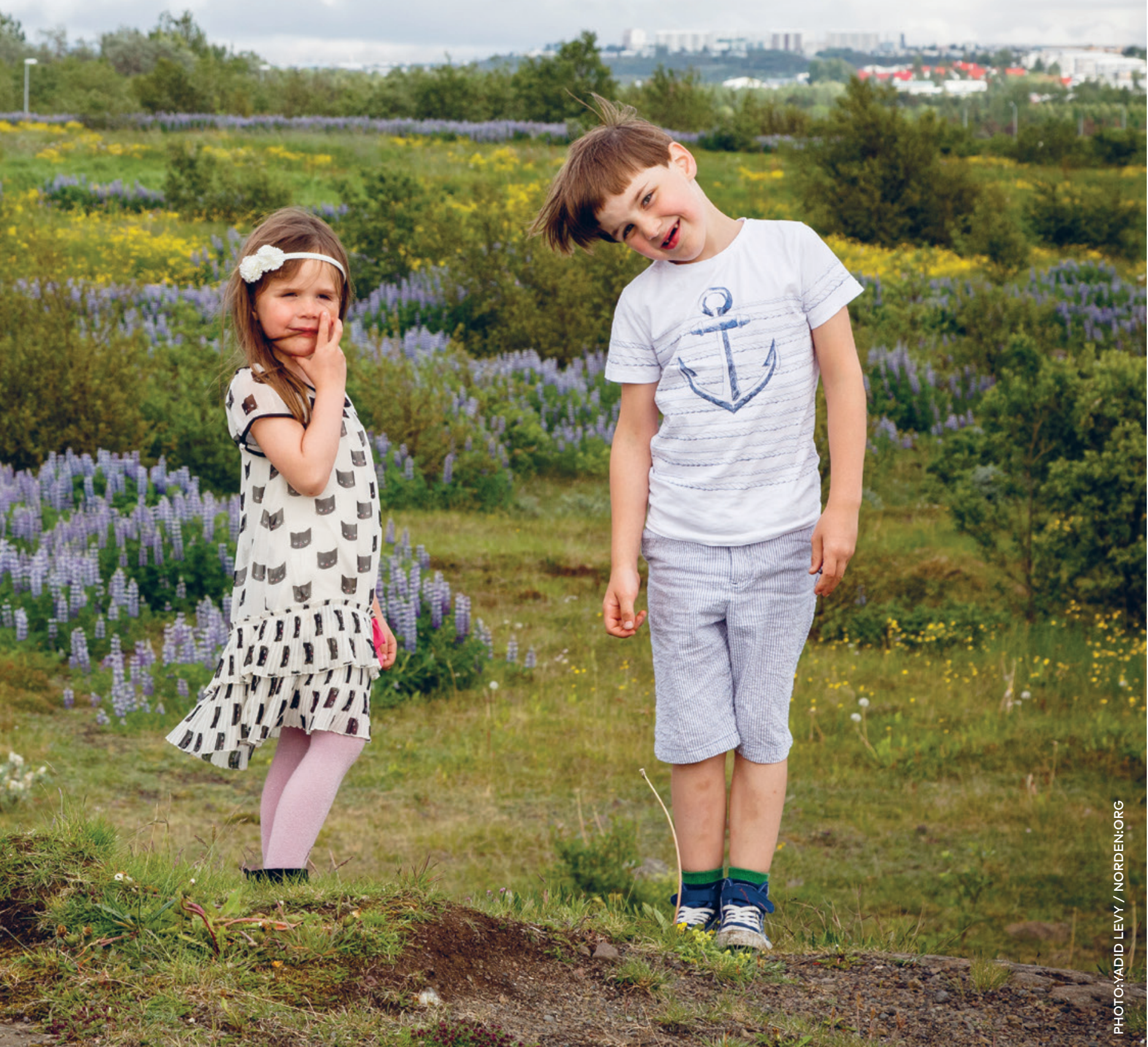


experience and specific initiatives. However, a new Nordic initiative in this field was represented at the meeting of housing and construction ministers on 29 May 2018, at which the ministers stated that they will promote a strengthened and integrated construction market in the Nordic region.

It is therefore proposed that, under the aegis of the Nordic Council of Ministers, cross-sectoral co-operation be established between the Nordic social and housing ministers, in order that the ministers, together with relevant actors in the Nordic region, can discuss the development of housing in the Nordic region in relation to social policy objectives, and continuously identify opportunities for Nordic co-operation in housing. This may also be relevant to other sectors of the Nordic co-operation, such as the energy, climate and business sectors, and to the Nordic co-operation on the UN's Sustainable Development Goals. Collaboration on housing could also focus on the potential of Nordic initiatives to bring about lower construction costs through more uniform building standards for accessibility and universal design.

A Nordic co-operation on housing should involve relevant actors in the housing field in the countries concerned, and allow for a broad debate and exchange of experience on how housing initiatives can contribute to advancing social policy objectives in the countries. One example is the way in which housing associations in the Nordic countries have established co-operation under the aegis of the Nordic Association NBO - Housing Nordic, which, inter alia, provides a framework for the exchange of experience and co-operation in the field of co-operative and municipal housing among the NBO members, which number Denmark, Finland, Iceland, Norway and Sweden. NBO Housing Nordic, and other key actors working with housing-related issues, could be actively involved in Nordic social and housing policy collaboration.
NBO, for example, compiles a report every two years which gives an overall view of developments, trends and challenges in the housing market in the Nordic countries. The report also contains proposals that could be included in discussions in the Nordic Council of Ministers. The most recent report was presented at a conference in Stockholm in August 2018.

Overall, it is proposed that collaboration be established between the Nordic ministers for housing and social welfare, which, for example through ministerial conferences, high-level meetings and initiatives, will launch Nordic housing policy initiatives relevant to the social field. Within such a framework, various topics could be discussed, such as:

- General trends in the field of housing, in the light of social conditions that illustrate strengths or challenges for the Nordic countries - for example on the basis of the annual report from NBO- Housing Nordic.

- Exchanges of experience on how non-market-based solutions can address housing shortages.

- Inclusive cities with different forms of housing offers and room for all.

- Analysis of the reasons for the high construction costs in the Nordic region, and possible solutions.

- Social housing efforts in municipal and co-operative housing.

- Common Nordic standards for accessibility and universal design in relation to housing.

- New forms of housing for the elderly, e.g. housing collectives.

- Housing for people with disabilities, the socially vulnerable and the homeless.

In addition to their relevance to housing and social welfare, several of the themes also have connections with other sectors, such as the energy, 
climate and business sectors, as well as with the co-operation between the housing and construction ministers.

\section{PROPOSAL 13: SPARSELY-POPULATED AREAS}

The Nordic region is a large geographical area in which there are many sparsely-populated regions.

These provide the Nordic region with great cultural and natural riches, and include great human resources. Several structural tendencies in the Nordic societies are however influencing social living conditions for the populations of these areas. Due to demographic trends, several of these areas are characterised by aging populations and depopulation, partly because of fewer local possibilities for education and employment.

There are a number of particular challenges associated with providing social services of adequate scope and high quality in sparsely-populated areas. There are for example major challenges associated with providing care for the elderly and offers for children, the socially vulnerable and people with disabilities in areas where there are large geographical distances and a small population. The challenges here include recruitment of qualified welfare personnel and the maintenance of professional environments with the necessary level of knowledge. In addition, it is important from a social policy perspective to prevent these structural conditions resulting in an increased risk of marginalisation for men and women living and growing up in small communities.

It is proposed that the Nordic co-operation launches initiatives aimed at exchanging and developing knowledge on how social services can be delivered in a resource-efficient manner, in the necessary scope and to the necessary degree of quality, in sparsely-populated areas. It is furthermore proposed that initiatives be launched on how to secure good possibilities for education, work and participation in society for children and young people who grow up in sparsely-populated areas.

Various kinds of initiatives could be considered, such as:

- Co-operation on social innovation, with a particular focus on social services in sparsely-populated areas, for example through the use of mobile services, welfare technology and digitalisation.

- Exchanges of experience on the organisation of social services in sparsely-populated areas, including co-operation across administrative bodies and collaboration between the Nordic countries in the social field in sparsely-populated border regions.

- Exchanges of experience in relation to the efforts of the countries to recruit and further qualify staff in sparsely-populated areas.

- Exchanges of experience on efforts to promote the inclusion of young men and women in education and the labour market in sparsely-populated areas (see also proposal 8 on children and young people).

- Promoting the maintenance and formation of social networks in sparsely-populated areas through the efforts of voluntary organisations. Nordic networks or platforms could for example be established between voluntary organisations, cross-municipal associations and national authorities to provide inspiration for local and regional efforts in this field.

\section{PROPOSAL 14: INTERNATIONAL CO- OPERATION}

In its co-operation programme, the Nordic Council of Ministers for Health and Social Affairs has focused on promoting co-operation on EU issues of common Nordic interest, where this is relevant in relation to the EU's early legislative and decision-making phase, prior to the presentation 


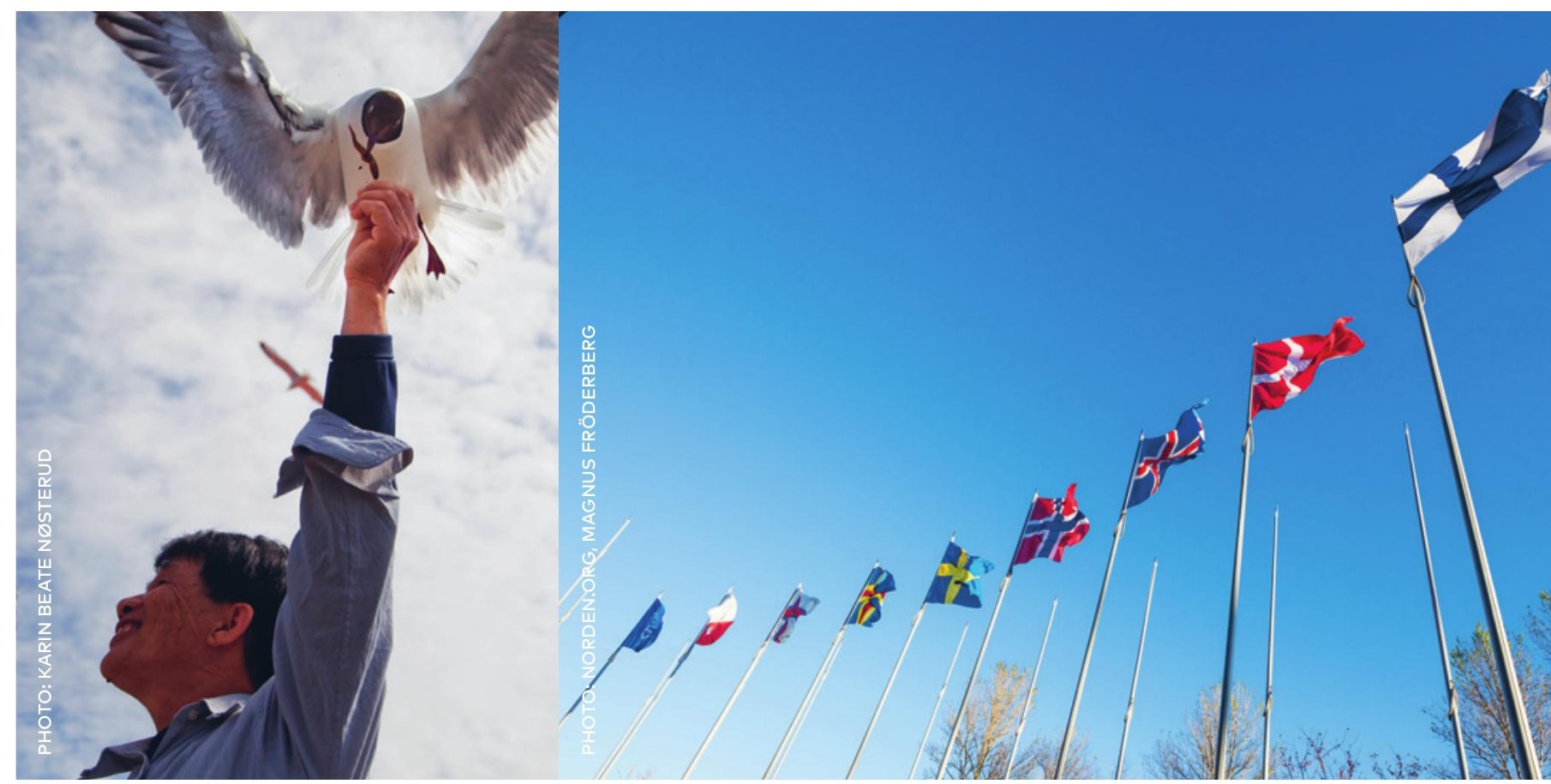

of proposals by the EU Commission, and in the subsequent implementation of EU legislation in the field of social and health care.

There is no doubt that there is great interest in the Nordic welfare model and the Nordic social systems in the EU Commission and the OECD, and that there is a focus on social policy in a broad sense.

Several of the activities and initiatives undertaken or implemented by the Nordic Council of Ministers for Health and Social Affairs also have a European or international dimension. This applies, for example, to the field of disability, where the United Nations Convention on the Rights of Persons with Disabilities is an example of an important basis for the work of the Council for Nordic Co-operation on Disability. Another example is Regulation (EC) no. 883/2004 of the European Parliament and of the Council of 29 April 2004 on the co-ordination of the social security systems of the member countries. Here, a great deal of work is done between the Nordic countries in relation to changes in the Regulation and the interpretation of its provisions. This takes place partly in the Administrative Commission for the Coordination of Social Security Systems, which is established on the basis of Regulation 883/2004, and partly in the Nordic Social Insurance Group, which takes its mandate from MR-S.

The social field has gained increasing importance in the EU co-operation, and the EU co-operation is quite extensive in the social field, although it is predominantly characterised by national competence. The social field directly impacts the lives and living conditions of everyone, and questions of competence between national and EU competence are an ongoing EU-wide debate in this area.

It is therefore proposed that the Nordic Council of Ministers for Health and Social Affairs should to a greater extent utilise its co-operation to draw 
upon, obtain and discuss relevant knowledge from the EU and international organisations dealing with social affairs, and focus on Nordic co-ordination in connection with meetings or other activities to promote Nordic viewpoints in these fora. At the same time, there should also be a focus on what the Nordic countries can contribute in useful experience and innovative ways and methods, which could both strengthen the profiling of the Nordic region in the social field and help to protect the Nordic welfare model. The co-operation could usefully be based around specific topics or proposals, such as the OECD project "Faces of Joblessness: Understanding employment barriers to inform policy", which is also relevant in the work with vulnerable adults and their access to the labour market, cf. proposal 9. The European Pillar of Social Rights will place a new focus on the European social dimension, and could result in new EU acts which will be relevant at Nordic level. A third example could be the implementation of the EU Accessibility Directive. Consideration could be given to discussing the annual country-specific recommendations from the EU Commission in the
Nordic Council of Ministers for Health and Social Affairs, with the aim of keeping close contact and supporting each other in maintaining and explaining the Nordic welfare model. This is not only relevant for the three Nordic countries who are members of the EU, but also for the two other countries, who to a large extent implement EU legislation in the social field due to the EEA Agreement.

Finally, it is proposed that in the Nordic initiatives in the social field, a greater focus should in general be placed on knowledge obtained from countries outside the Nordic countries and from international organisations, especially the EU, the OECD and the UN organisations. The Nordic initiatives in the social field are most often aimed at enabling the Nordic countries to learn from each other. This remains highly relevant, but it is assessed that the Nordic co-operation could also turn its gaze outward and be used as a common base for retrieving state-of-the-art knowledge in the social field from further afield. 

Nordic Council of Ministers

Nordens Hus

Ved Stranden 18

DK-1061 Copenhagen K

www.norden.org

In 2017, the Nordic Council of Ministers for Health and Social Affairs (MR-S) decided to carry out a strategic review of the Nordic co-operation in the social sector. The aim was to develop and strengthen the Nordic co-operation in the social field to ensure that it was adapted to the needs of the Nordic countries and current issues, and produced concrete results. The review was to result in a report with proposals that MR-S and the Committee of Senior Officials for Health and Social Affairs (EK-S) could apply to develop both the existing co-operation and new initiatives, in a 5-10-year perspective.

The review has been carried out by Árni Páll Árnason, former Minister of Social Affairs and Social Security and Minister of Economic Affairs in Iceland, who has drawn up an independent report with 14 proposals to strengthen Nordic co-operation in social policy, following consultations with actors in the social field both inside and outside the Nordic Region.

This report is part of a series of strategic and forward-looking studies carried out by the Nordic Council of Ministers. The report is an element in the Nordic Council of Ministers' reform project. Previous strategic reviews have dealt with co-operation in the areas of health, the labour market, legislation, energy and environmental policy. 